\author{
A Thesis \\ Presented to
}

The Faculty of Graduate Studies

of

The University of Guelph

by

KEVIN ANDREW JUDGE

In partial fulfillment of requirements

for the degree of

Master of Science

September, 1999

- Kevin Andrew Judge, 1999 
National Library

of Canada

Acquisitions and Bibliographic Services

395 Wellington Street Onawa ON KIA ONA Canada
Bibliothèque nationale du Canada

Acquisitions et services bibliographiques

395. ne Wellington Ottawa ON K1A ON4 Canada
The author has granted a nonexclusive licence allowing the National Library of Canada to reproduce, loan, distribute or sell copies of this thesis in microform, paper or electronic formats.

The author retains ownership of the copyright in this thesis. Neither the thesis nor substantial extracts from it may be printed or otherwise reproduced without the author's permission.
L'auteur a accordé une licence non exclusive permettant à la Bibliothèque nationale du Canada de reproduire, prêter, distribuer ou vendre des copies de cette thèse sous la forme de microfiche/film, de reproduction sur papier ou sur format électronique.

L'auteur conserve la propriété du droit d'auteur qui protège cette thèse. $\mathrm{Ni}$ la thèse ni des extraits substantiels de celle-ci ne doivent être imprimés ou autrement reproduits sans son autorisation. 


\section{ABSTRACT \\ CHORUS PARTICIPATION BY MALE BULLFROGS, RANA CATESBEIANA: A TEST OF THE ENERGETIC CONSTRAINT HYPOTHESIS}

Kevin Andrew Judge

University of Guelph, 1999
Advisor:

Professor R.J. Brooks

Chorus tenure is the number of nights that a male spends attending choruses, and dominant tenure is the number of nights that a male adopts a dominant mating tactic. While male bullfrogs (Rana catesbeiana) that have longer tenure (chorus tenure and dominant tenure) acquire more mates, tenure is believed to be energetically costly. I tested the hypothesis that tenure of bullfrogs is energy-constrained by conducting a feeding experiment to manipulate energetic condition, and by measuring each male's body condition on every night of chorus tenure. Male bullfrogs with longer tenure, other things being equal, were in better initial condition, poorer final condition and were more energetically efficient than males with shorter tenure. However, fed males did not attend choruses longer than unfed males, and males that temporarily left chorusing did not return in better condition than when they left. The energetic constraint hypothesis adequately explained abbreviated chorus tenure and there is evidence that sexual selection by endurance rivalry favoured increased energetic efficiency by male bullfrogs. 


\section{ACKNOWLEDGEMENTS}

I deliberated long and hard on how to write acknowledgements to the many people who've made important contributions of physical labour, brain power, money and sanity towards the completion of this project. The problem is that, when so many people have had a positive influence on a Master's thesis, and in so many ways, how do I, 1) accurately attribute specific instances of help to individuals; 2) acknowledge all influential parties; and 3) avoid including everyone that I know. The following is the result of tradeoffs between: the limits of my memory, the limits of the reader's patience, and spatial and energetic efficiency. It's up to the reader to test hypotheses concerning the relative importance of each of these factors.

\section{Thank you from the bottom of my heart:}

Wojtek Archiczewski ${ }^{1}$, Sara Ashpole ${ }^{2}$, Jim Atkinson ${ }^{3}$, Niki Boyd $^{4}$, Ron Brooks ${ }^{5}$, Bullfrogs $^{6}$, Matt Cornish', Dave Cunnington ${ }^{8}$, Yemisi Dare, Shane de Solla ${ }^{10}$, Julia Durham ${ }^{11}$, Darren Elder ${ }^{12}$, Jon Edmonds ${ }^{13}$, Lisa Enright ${ }^{14}$, Fowler Construction Co. $^{15}$, Sarah Holt ${ }^{16}$, Ian Hornsby ${ }^{17}$, Carys Jones $^{13}$, Jeannie Judge ${ }^{19}$, Terry Judge ${ }^{20}$, Tim Judge $e^{21}$, Nicky Koper $^{22}$, Marc Lange $^{23}$, Doug Larson ${ }^{24}$, Janet Lochead ${ }^{25}$, Tristan Long ${ }^{26}$, Cam MacDonald ${ }^{27}$, Art MacMaster ${ }^{28}$, Elaine Matthews ${ }^{29}$, Rob MCLaughlin ${ }^{3 \mathrm{C}}$, Keith MTaggart ${ }^{31}$, Seanna M'Taggart ${ }^{32}$, Sandy Middleton ${ }^{33}$, Graham Nancekivell ${ }^{34}$, NSERC ${ }^{35}$, Tom Nudds ${ }^{36}$, Johanne Paquer ${ }^{37}$, Ben Porchuk ${ }^{38}$, Bridget Roche ${ }^{39}$, John Roff ${ }^{40}$, Lindsay Sachro $^{+1}$, Kurt Schryer ${ }^{42}$, Albrecht Schulte-Hostedde ${ }^{43}$, Adam Soward ${ }^{44}$, Kim Smith ${ }^{45}$, Lindsay Snow ${ }^{46}$, Sarah Swanson ${ }^{47}$, Michelle Theberge ${ }^{48}$, Shem Unger ${ }^{49}$, University of Guelph ${ }^{56}$, Rob Van Vlaenderen $^{51}$, Michelle Wagner ${ }^{52}$, Val Wemp-Rochefort ${ }^{53}$, Rob Wilison ${ }^{54}$, John Winter ${ }^{55}$, Lin Wong $^{56}$ 
For:

Advice, experimental design: $3,5,27,30,36,47$

Advice, statistics: $10,23,30,36$

Advisor: 5

Advisory committee: $5,30,36$

Beaver dam control: $5,16,21,31,47$

Comrades in Brooksland: $2,8,10,13,14,16,22,25,27,29,32,38,43,45,51,54$

Conception: 19,20

Constructive criticism of various drafts of my thesis proposal: $5,10,12,27,29,30,36,39,40,43$

Constructive criticism of various drafts of my thesis: $5,10,26,32,30,33,36,47,56$

Dam construction/Rebuilding study site: $5,7,15,55$

Dam engineering/design:

Field assistance: $1,6,9,16,18,21,27,28,37,39,49,51,52$

Field assistants: $4,31,41,46,47$

Rides to and from WRS: $5,19,21,27,37,40,43$

Study animals: 6

Support, emotional: $6,19,37$

Support, financial: $5,35,50$

Support, motivational: $5,6,17,24,25,27,33,34,37,38,43,48$

Support, nutritional: $11,19,28,37,53$

WRS staff: $1,7,11,28,42,44,53$ 


\section{TABLE OF CONTENTS}

Acknowledgements

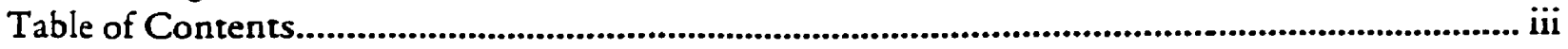

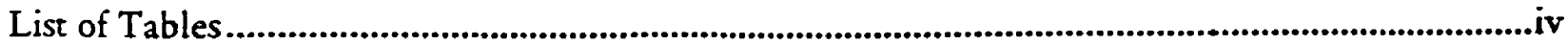

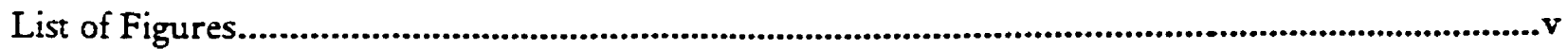

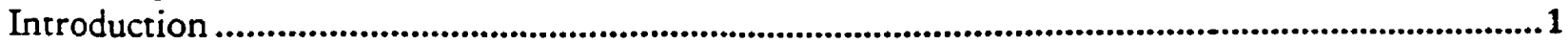

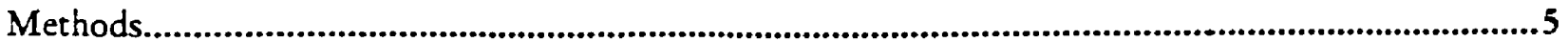

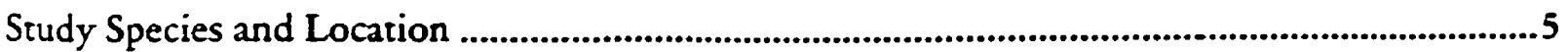

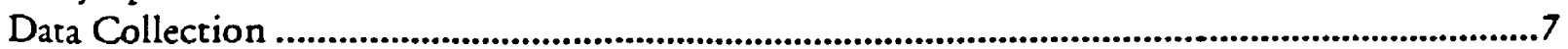

Tests of the Energetic Constraint Hypothesis.......................................................................8

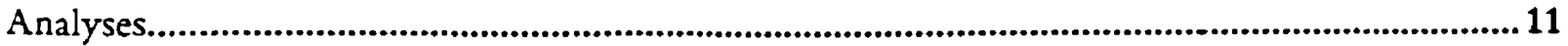

Interannual Comparisons of Chorusing Seasons .......................................................................13

Alternative Explanations of Abbreviated Tenure ..................................................................14

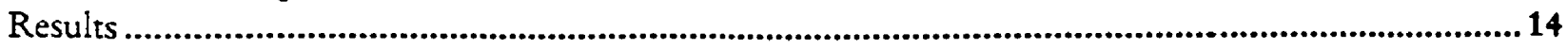

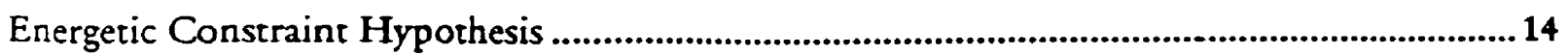

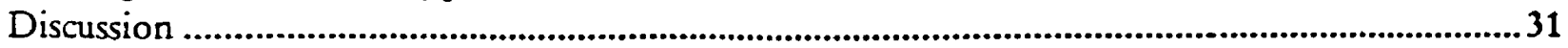

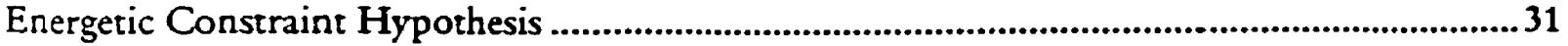

Interannual Comparisons of Chorusing Seasons .......................................................................... 36

Alternative Explanations of Abbreviated Tenure......................................................................36

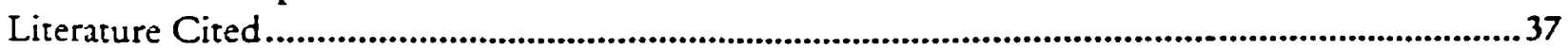

APPENDIX 1: INTERANNUAL COMPARISONS OF CHORUSING SEASONS ............43

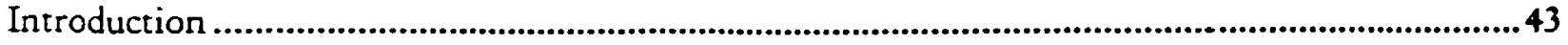

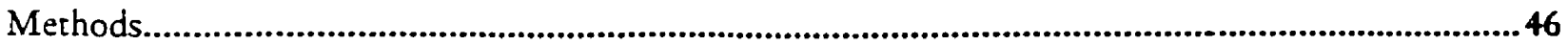

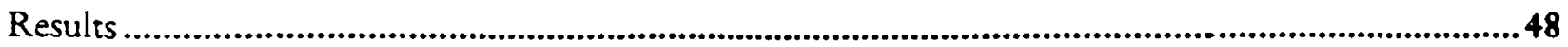

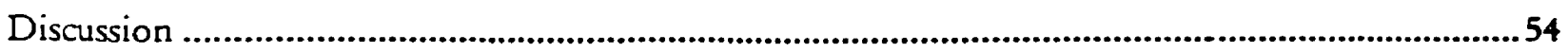

APPENDIX 2: ALTERNATIVE EXPLANATIONS OF ABBREVIATED TENURE..........56

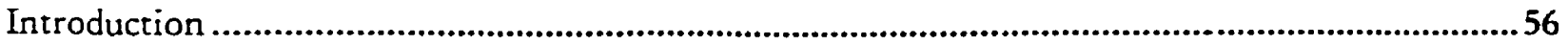

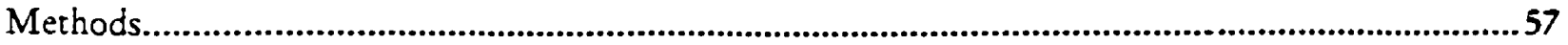

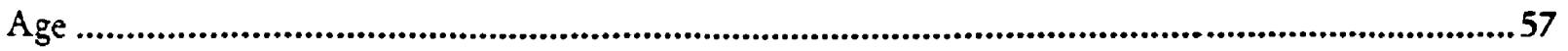

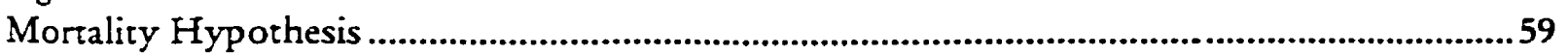

Movement Hypothesis .........................................................................................................5 59

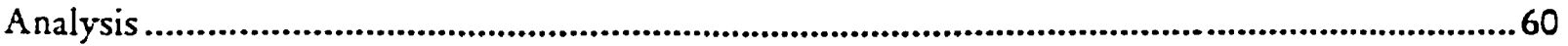

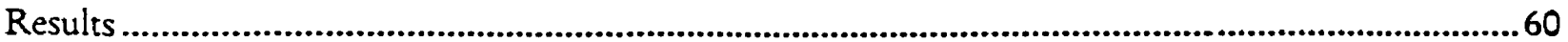

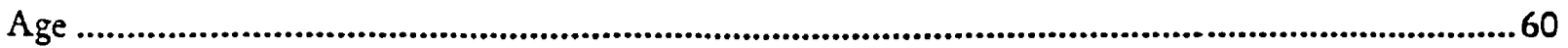

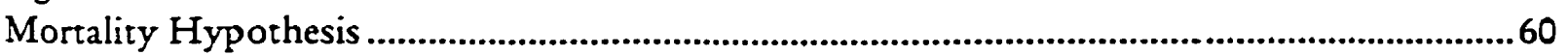

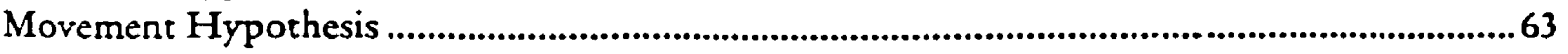

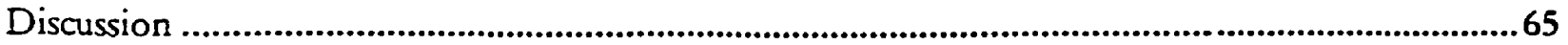

Age

Mortality Hypothesis ..............................................................................................................6 65

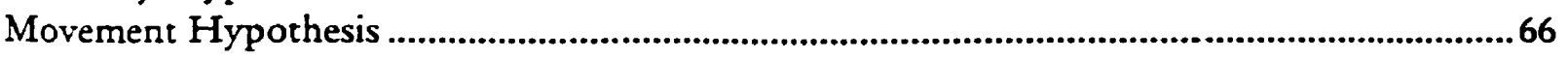

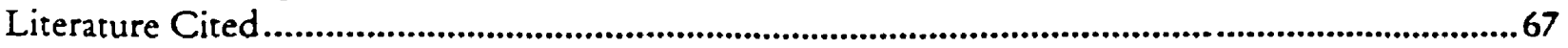

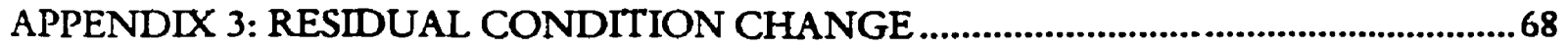

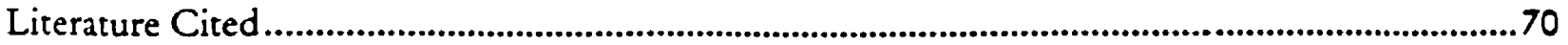




\section{LIST OF TABLES}

Table

1 A review of the relationship between chorus tenure and mating success for anurans.

2 Summary of the results of the multiple regression of chorus tenure on initial condition, final condition, residual condition change and feeding status.

3 Summary of the results of the multiple regression of dominant tenure on initial condition, final condition, residual condition change and feeding status.

4 Summary of the results of the ridge regression of chorus tenure on initial condition, final condition, residual condition change and feeding status.

5 Summary of the results of the ridge regression of dominant tenure on initial condition, final condition, residual condition change and feeding status.

6 Summary of male bullfrog temporary absences during the 1998 chorusing season.

7 Comparisons of initial condition, final condition, residual condition change, feeding status and condition change during absences, between male bullfrogs that survived the 1998 chorusing season and male bullfrogs that did not survive the 1998 chorusing season.

8 Comparisons of initial condition, final condition, residual condition change, feeding status and condition change during absences, between male bullfrogs that were successful breeders and males that were not successful breeders.

A2.1 Adult male bullfrog mortality from all years of chorus tenure study. 


\section{LIST OF FIGURES}

Figure

1 Lake Sasajewun, Algonquin Provincial Park, Ontario, and nearby bodies of water.

2 The precondition and predictions of the energetic constraint hypothesis for tenure (chorus tenure and dominant tenure) in male bullfrogs.

3 Summary of the 1998 bullfrog chorusing season, Lake Sasajewun, Algonquin Park.

4 Frequency distribution of bullfrog: a) chorus tenure and b) dominant tenure.

$5 \quad$ Mean chorus tenure and dominant tenure of successful breeders and unsuccessful breeders.

6 Plot of condition change versus chorus tenure and dominant tenure. .

7 Error bar plots of mean: a) final condition and b) residual condition 20 change for fed and unfed male bullfrogs.

8 Partial regression plots of chorus tenure residuals versus the residuals of: a) 24 initial condition, b) final condition, c) residual condition change and d) feeding status.

9 Partial regression plots of dominant tenure residuals versus the residuals of: a) initial condition, b) final condition, c) residual condition change and d) feeding status.

A1.1 Relative change in water level of Lake Sasajewun during the summer of 1998.

A1.2 Lake Sasajewun, Algonquin Provincial Park, Ontario.

A1.3 Plot of mean initial size of male bullfrogs participating in chorus activity from 1994 to 1998.

A1.4 Plot of mean initial condition of male bullfrogs participating in chorus 50 activity from 1994 to 1998.

A1.5 Plot of mean final condition of male bullfrogs participating in chorus 51 activity from 1994 to 1998.

A1.6 Plot of mean condition change of male bullfrogs participating in chorus 52 activity from 1994 to 1998.

A1.7 Plot of mean residual condition change of male bullfrogs participating in 53 chorus activity from 1994 to 1998.

A2.1 Plot of mean: a) chorus tenure and b) dominant tenure of the three experience classes for the 1998 chorusing season.

A2.2 Relationship between body size and: a) chorus tenure and b) dominant tenure for the 1998 chorusing season.

A2.3 Distribution of final nights of chorus tenure of male bullfrogs and 64 observations of snapping turtles for the 1998 chorusing season.

A3.1 Predicted relationship between rate of change in condition and chorus $\quad 71$ tenure.

A3.2 Relationship between tenure span and chorus tenure for the 1998 bullfrog 72 chorusing season on Lake Sasajewun.

A3.3 Plot of condition change versus tenure span with the least squares regression line for the 1998 bullfrog chorusing season on Lake Sasajewun. 


\section{INTRODUCTION}

Many animal species have evolved mating systems where females visit aggregations of males to select mates. In anurans, these aggregations are called choruses because the males vocalize to attract females. An individual male's attendance at choruses, measured in number of nights, is called chorus tenure (Murphy 1994a). Males have a low probability of acquiring a mate on any given night if female arrival at choruses is spread out over time and the operational sex ratio (OSR) is highly male biased (Emlen and Oring 1977). However, males can increase their probability of mating by increasing their attendance at breeding aggregations (Gerhardt et al. 1987, Halliday and Tejedo 1995). Thus, traits that increase male persistence or stamina at the chorus will be favoured by sexual selection. This form of male competition for access to gravid females is called endurance rivalry (Andersson 1994). Although a large number of studies have found a positive relationship between male attendance at breeding aggregations and mating success (Table 1), endurance rivalry has probably been underrepresented in studies of sexual selection (Andersson 1994, Andersson and Iwasa 1996).

Most male anurans display highly abbreviated chorus tenures relative to the entire breeding season despite apparent sexual selection favouring increased chorus tenure (Murphy 1992). Males are thought to restrict their chorus tenure because it is costly in terms of: a) increased predation risk (reviewed in Magnhagen 1991), b) lost foraging opportunities (Woolbright and Stewart 1987) and c) increased energy consumption (reviewed in Pough et al. 1992). Calling is the most energetically expensive activity undertaken by anurans (Pough et al. 1992). However, chorus tenure also involves males expending energy in aggressive interactions with conspecifics, and in inter- and intra-chorus locomotion. The energetic cost of chorus tenure, measured as male weight loss over the chorusing season, has been documented for a large number of frog species 
Table 1. A review of the relationship between chorus tenure and mating success for anurans.

\begin{tabular}{|c|c|c|}
\hline Species & $\begin{array}{l}\text { Relationship between Chorus } \\
\text { Tenure and Mating Success }\end{array}$ & Reference \\
\hline Buergeria buergeri & + & Fukuyama and Kusano unpubl. \\
\hline Bufo americanus & + & Gatz 1981 \\
\hline B. bufo & ? & Davies and Halliday 1979 \\
\hline \multirow[t]{3}{*}{ B. calamita } & + & Arak 1983b, 1988 \\
\hline & + & Tejedo 1992 \\
\hline & + & Denton and Beebee 1993 \\
\hline B. canorus & + & Kagarise Sherman $1980 \ddagger$ \\
\hline B. cognatus & + & Sullivan 1982a \\
\hline B. exsul & $t^{*}$ & Kagarise Sherman $1980 \ddagger$ \\
\hline B. gutteralis & + & Telford and Van Sickle 1989 \\
\hline B. rangeri & + & Cherry 1993 \\
\hline \multirow[t]{2}{*}{ B. valliceps } & $?$ & Blair 1960 \\
\hline & + & Wagner and Sullivan 1995 \\
\hline \multirow[t]{4}{*}{ B. woodhousei } & + & Woodward 1982 \\
\hline & + & Sullivan $1982 b$ \\
\hline & $+\bullet$ & Sullivan 1987 \\
\hline & 0 & Sullivan 1989 \\
\hline \multirow[t]{2}{*}{ Centrolenella fleischmanni } & + & Greer and Wells 1980 \\
\hline & + & Jacobson 1985 \\
\hline C. prosoblepon & + & Jacobson 1985 \\
\hline Chiromantis xerampelina & + & Jennions et al. 1992 \\
\hline Eleutherodactylus coqui & + & Townsend and Stewart 1994 \\
\hline Epipedobates trivittatus & $\infty$ & Roithmair 1994 \\
\hline \multirow[t]{3}{*}{ Hyla chrysoscelis } & + & Godwin and Roble 1983 \\
\hline & + & Morris 1989 \\
\hline & + & Ritke and Semlitsch 1991 \\
\hline H. cinerea & + & Gerhardt et al. 1987 \\
\hline H. faber & + & Martins 1993 \\
\hline H. gratiosa & + & Murphy $1994 a$ \\
\hline H. regilla & $?$ & Perrill 1984 \\
\hline H. rosenbergi & + & Kluge 1981 \\
\hline \multirow[t]{2}{*}{ H. versicolor } & 0 & Fellers 1979 \\
\hline & + & Sullivan and Hinshaw 1992 \\
\hline Hyperolius marmoratus & + & Dyson et al. 1992 \\
\hline Physalaemus pustulosus & + & Ryan 1983 \\
\hline Rana catesbeiana & + & MacDonald 1997, this study \\
\hline R. clamitans & + & Wells 1976 $\ddagger$ \\
\hline$R$. virgatipes & + & Given $1988 b$ \\
\hline Scinax boulengeri & $?$ & Bevier 1997 \\
\hline S. rubra & $?$ & Bevier 1997 \\
\hline
\end{tabular}


(e.g. Wells 1978, Arak 1983a, Robertson 1986, Given 1988a, Ryser 1989, Murphy 1994b, MacDonald 1997).

Andersson (1994) stated that endurance rivalry should favour efficiency in the acquisition and use of energy by males. However, energetic constraint of chorus tenure must be demonstrated before sexual selection favouring increased energetic efficiency can be tested. Energetic constraint is distinct from energetic cost in that the former is a precondition of the latter (e.g. energetically inexpensive behaviours are probably less constrained by energy). Also, energetic constraint implies that, given knowledge of an individual's energetic condition, one can make specific predicticns about behaviour, whereas no such predictions are possible from a simple knowledge of the energetic cost.

Murphy (1994b) developed the energetic limitation hypothesis to explain variation in the chorus tenures of male barking treefrogs (Hyla gratiosa). He hypothesized two time periods over which energetic constraint (constraint $=$ physiological constraint, as in Stearns 1992) might operate before chorus tenure begins, and/or during chorus tenure. If energetic constraint operates before chorus tenure begins, then males with longer chorus tenures should display at least one of the following, 1) better initial body condition; 2) poorer final body condition; and 3) slower rate of body condition decline relative to males with shorter chorus tenures. If energetic constraint operates during chorus tenure, then males that increase body condition during chorus tenure (i.e. through greater foraging success) should have longer chorus tenures than males that do not (Murphy 1994b). However, Murphy's distinction between energy constraint acting before versus during chorus tenure is artificial, because the predictions associated with each period do not fall neatly into the two time periods and are highly dependent upon each other. For this reason, the effects of energy in the two time periods are difficult to distinguish experimentally. 
To avoid this confusion, I constructed an energetic constraint hypothesis without the distinction between constraint acting before or during chorus tenure. It predicts, analogous to Murphy (1994b), that, other things being equal, 1) males in better initial energetic condition will have longer chorus tenures than males in poorer initial energetic condition; 2) males in poorer final energetic condition will have had longer chorus tenures than males in better final energetic condition; 3) males that lose less condition than expected over a given amount of time (i.e. are more efficient) will have longer chorus tenures than males that lose more; and 4) males that are more successful foragers will have longer chorus tenures than males that are less successful.

Bullfrog chorus attendance is not continuous (MacDonald 1997), so I added one prediction to the energetic constraint hypothesis to examine the relationship between absences within a bullfrog's chorus tenure and energetic condition. If male bullfrogs temporarily leave chorusing to recoup lost body condition, then I predict (5) that when they return, males should be in better condition than when they left (Bevier 1997).

Based on Howard's (1978) classification of bullfrog mating tactics, chorus tenure can be subdivided into chorus tenure spent as a dominant male (dominant tenure) and chorus tenure spent as a subordinate male (subordinate tenure = tenure spent: as a satellite male, as an opportunistic male or in an indeterminate posture). Dominant or territorial male bullfrogs call and actively defend territories from other male bullfrogs. They maintain an inflated posture with their throats and backs above the surface of the water, and they move less and fight more than subordinate bullfrogs (Emlen 1976, Howard 1978). Males that exhibit the dominant tactic achieve higher mating success than males that do not (Howard 1978). The energetic costs of chorus tenure may be more severe in dominant males than subordinate males. If so, predictions one to four of my energetic constraint hypothesis should hold true for both chorus tenure and dominant tenure, 
but not subordinate tenure. Although chorus tenure and dominant tenure are highly correlated, I conducted parallel analyses for both chorus tenure and dominant tenure throughout this thesis. Analyzing chorus tenure allows me to make comparisons with other studies, and analyzing dominant tenure allows me to examine a variable that may be more relevant to selection than chorus tenure.

\section{METHODS}

\section{Study Species and Location}

Bullfrogs are large-bodied, prolonged-breeding (Wells 1977) anurans widely distributed across most of the eastern United States and into south-eastern Canada. In Algonquin Provincial Park, Ontario, they are near the northern limit of their distribution (Conant and Collins 1998), and mature later and at a smaller size than bullfrogs from more southern populations (Shirose et al. 1993). Research was conducted within the Wildlife Research Area of Algonquin Park, on Lake Sasajewun $\left(45^{\circ} 35^{\mathrm{N}}, 78^{\circ} 30^{\circ} \mathrm{W}\right)$ and the adjacent bodies of water (Figure 1). Lake Sasajewun (approximate surface area $\mathbf{4 3 . 5}$ ha, maximum depth $9 \mathrm{~m}$ ) was created as an artificial impoundment during the early 1900s (see Obbard 1977 and Shirose 1990 for more detailed site descriptions).

A large amount of information has been collected on the basic population ecology and mating system of bullfrogs on this lake (e.g. Shirose 1990, MacDonald 1997). Bullfrog chorusing on Lake Sasajewun lasts approximately six weeks, from early June to late July. Males chorus from seven main sites around the margin of the lake. These chorusing sites have been highly conserved for the past five years (MacDonald 1997, pers. obs.) (Figure 1). Chorus tenure and dominant tenure encompass only $25 \%$ and $10 \%$ of the breeding season respectively (MacDonald 1997, this study). Male bullfrogs exhibit a dominant/satellite/opportunistic mating strategy (MacDonald 


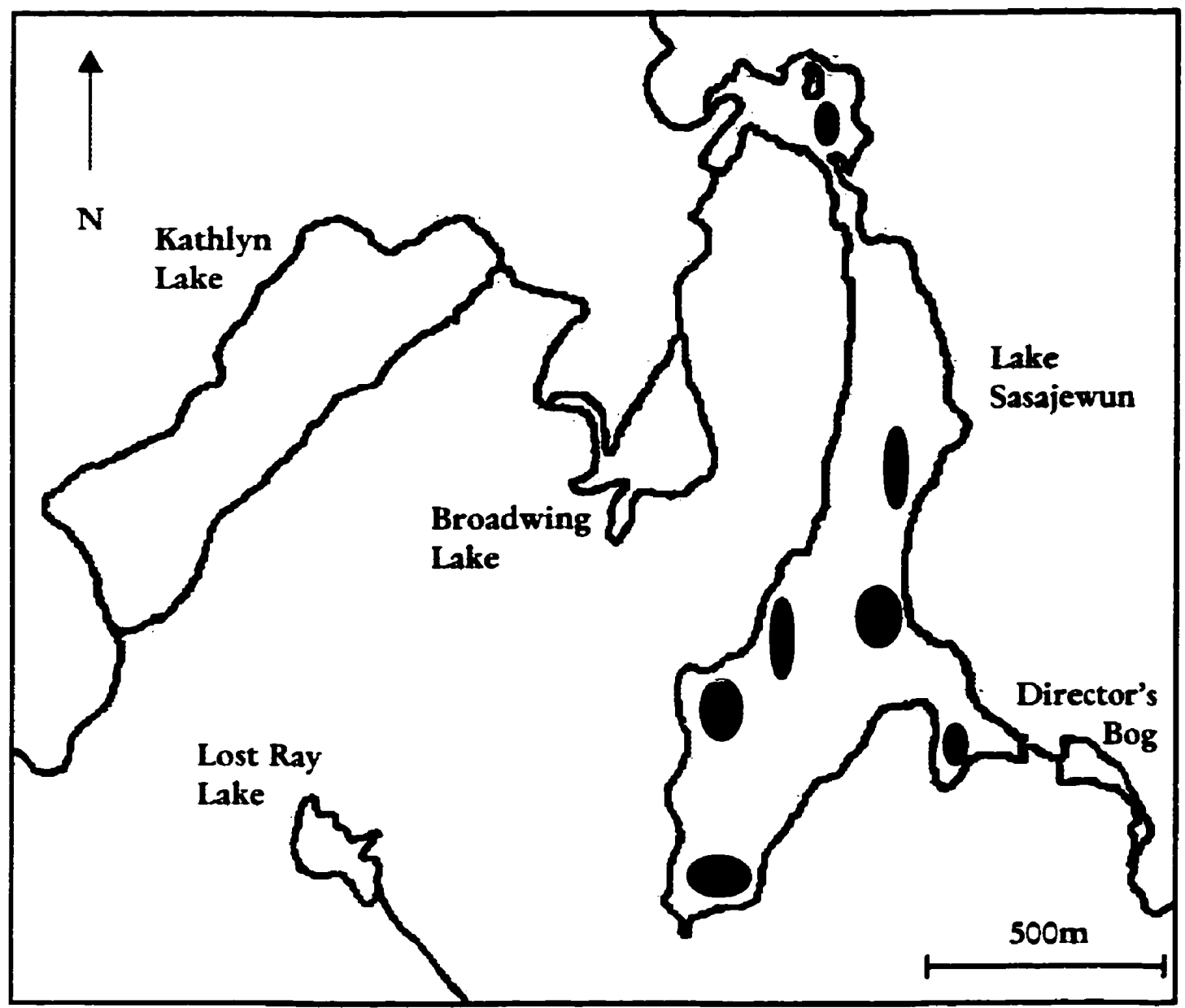

Figure 1. Lake Sasajewun, Algonquin Provincial Park, Ontario, and nearby bodies of water. Black ellipses represent the seven main bullfrog chorusing sites. 
1997). The large size of Lake Sasajewun made it impossible to consistently identify the opportunistic mating tactic described by Howard (1978); therefore, males in my study were classified only as being dominant or subordinate.

\section{Data Collection}

The Lake Sasajewun population of chorusing male bullfrogs was censused each night during the 1998 chorusing season. Field researchers searched the entire lake each night and visited every site (ranged from three to ten sites on a given night) at which bullfrogs were heard chorusing, either that night or within the previous five nights. Male bullfrogs were located from a canoe using a combination of the sound of bullfrog calls and the reflection of headlamp (Petzl $\mathrm{Mega}^{\star}$, halogen buib) light from bullfrogs' eyes. Once a chorusing site was located, bullfrogs were captured by dipnet either directly from the canoe or on foot (from the shoreline). Males were placed in one of two buckets according to their observed mating tactic (dominant or subordinate). While still at the chorus site, frogs were removed individually from the buckets, identified by individual alphanumeric tattoos, classified according to observed mating tactic and weighed on an electronic scale to the nearest $0.1 \mathrm{~g}$. Individuals were then returned to their chorus site within approximately $15 \mathrm{~min}$ of capture. The number of female frogs present in the chorus was also recorded. I varied the order of chorus censusing to reduce the chance of missing the participation of a bullfrog that may have consistently started or ended his nightly chorusing activities after or before we arrived at the chorus site.

New chorusing male bullfrogs were brought back to the lab after nightly chorus censuses had been completed (see above). Each new male was: measured (snout-urostyle length) to the nearest $0.1 \mathrm{~mm}$, toe clipped as part of an ongoing study into the efficacy of skeletochronology (MacDonald and Brooks 1997), implanted with a Passive Integrated Transponder (PIT) tag for 
individual identification (Brown 1997), given a unique alphanumeric tattoo on the belly (Shirose 1990) and weighed to the nearest 0.1g using an electronic scale (Acculab V-333 and V-400). All procedures sanctioned by the University of Guelph Animal Care Committee (Animal Utilization Protocol 98R072). Snout-urostyle length was measured five times for each individual to assess the precision of this measurement and to increase the accuracy by using the mean value.

At the end of the chorusing season, chorus tenure and dominant tenure estimates were counted for each male bullfrog that chorused on Lake Sasajewun. Male bullfrogs moved many times among choruses within Lake Sasajewun (pers. obs.); however, tenure estimates were summed across choruses. Because other bodies of water were censused infrequently, males that were observed attending choruses on other lakes were excluded from all analyses requiring chorus tenure and dominant tenure because of the likelihood that these estimates were underestimated. Data on chorus tenure, body size, initial body condition and mating success were collected for male bullfrogs that participated in the 1999 chorusing season.

All observations and measurements were verbally recorded on microcassette tape recorders and transcribed the following day.

\section{Tests of the Energetic Constraint Hypothesis}

If the energetic constraint hypothesis is true then males with longer tenures will, all things being equal, exhibit at least one of the following: 1) higher initial energetic condition, 2) lower final energetic condition, 3) higher residual condition change or 4) greater foraging success, relative to males with shorter tenures (Figure 2). Also, 5) if males temporarily leave chorusing to recoup lost body condition, then when they return, males should be in better condition than when they left. 


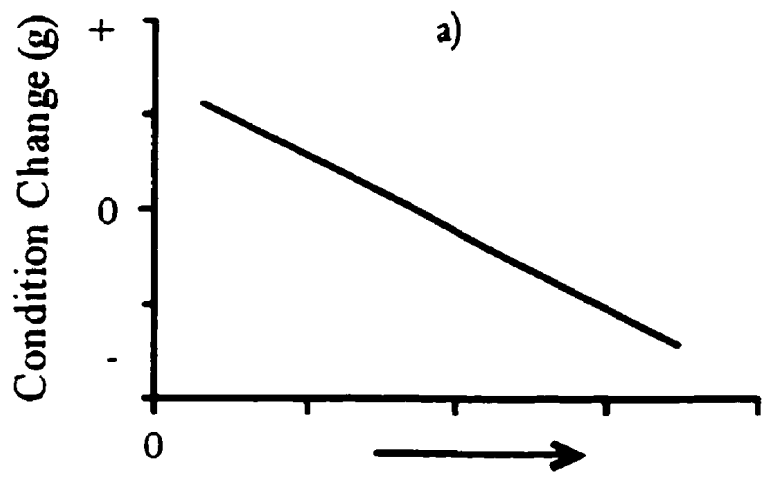

Tenure (nights)

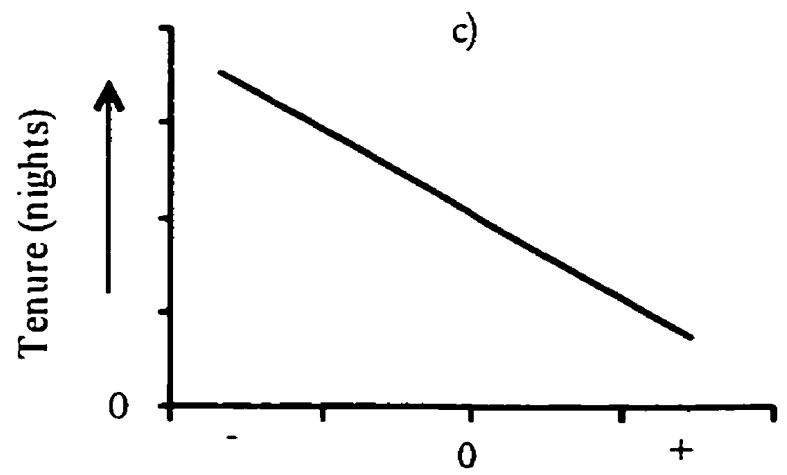

Final Condition (g)

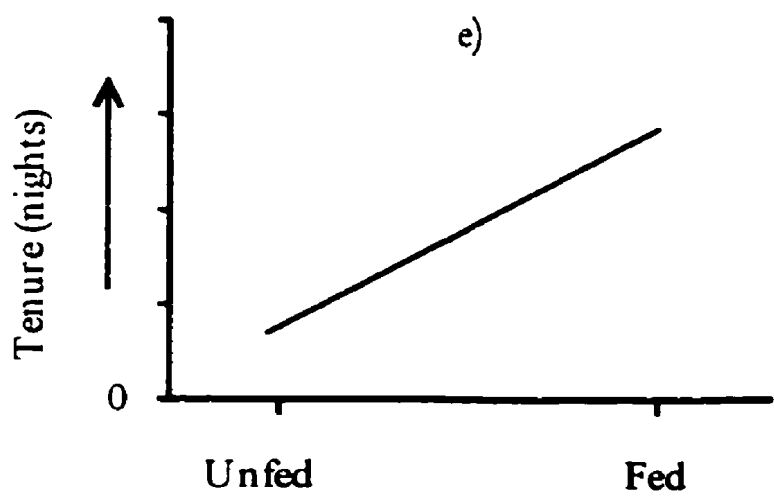

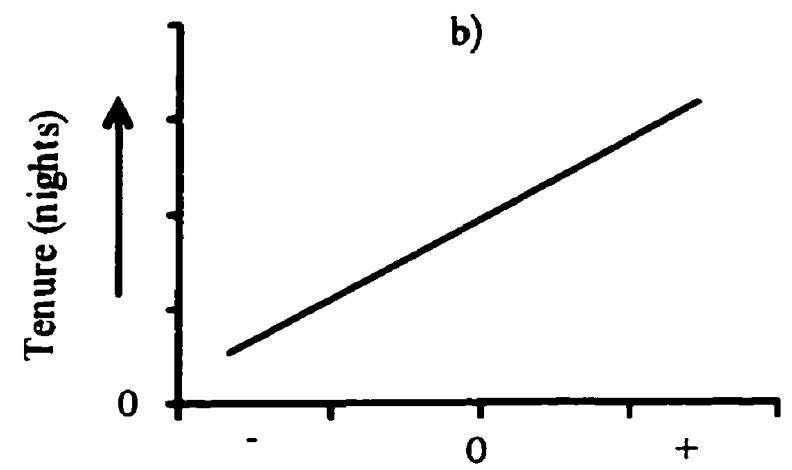

Initial Condition (g)
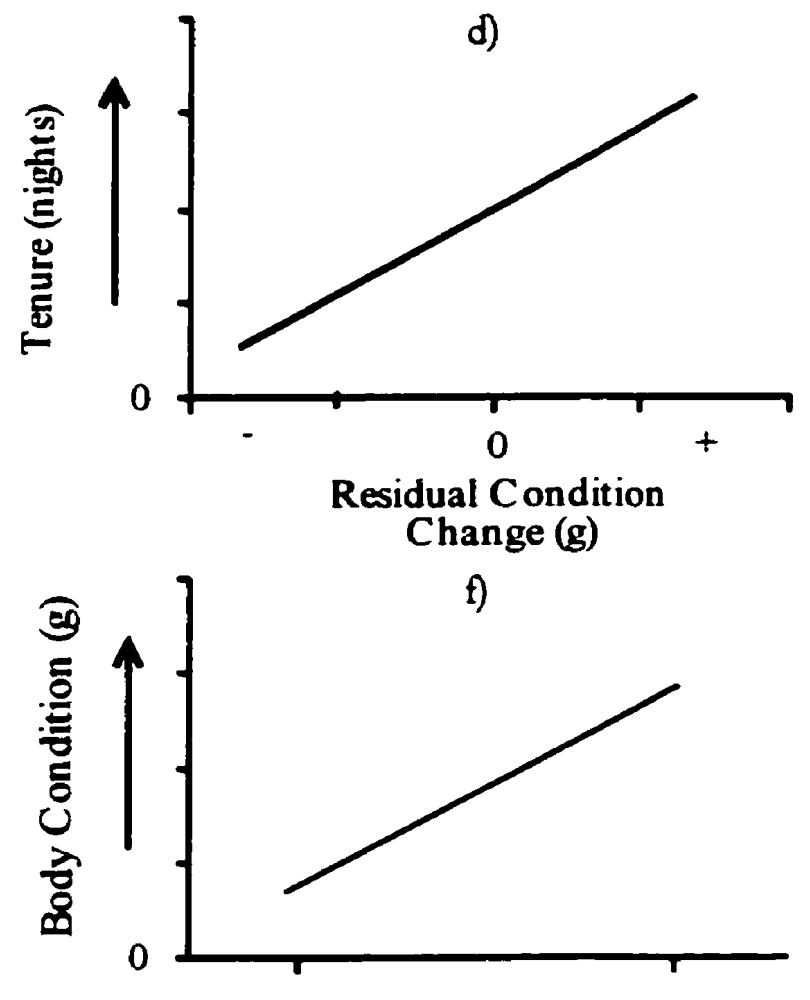

Before

After

Figure 2. The: a) precondition and b-f) predictions of the energetic constraint hypothesis for tenure (chorus tenure and dominant tenure) in male bullfrogs. Precondition: as tenure increases, so does loss of body condition (2a). Predictions: 1 ) initial condition will be positively related to tenure (2b), 2) final condition will be negatively related to tenure (2c), 3) residual condition change will be positively related to tenure (2d), 4) fed bullfrogs (successful foragers) will have longer tenures than unfed bullfrogs (unsuccessful foragers) (2e), and 5) body condition immediately after temporary absences from chorusing activity will be better than immediately before (2f). 
Predictions one, two and three were tested by observational means by calculating three measures of condition for each individual bullfrog and then examining their correlations with chorus tenure and dominant tenure. A male's initial condition was the deviation of his initial mass from the regression line of initial mass versus body size. Final condition was calculated by subtracting a male's predicted mass (given by the regression equation of initial mass on body size) from his final mass (measured on or within a week of his last night of chorus tenure). Residual condition change was calculated by subtracting final condition from initial condition and regressing this result against the number of nights spanned by those two measurements. This variable was used instead of rate of change in condition (Murphy 1994b) because I felt that using a ratio variable such as rate of change in condition (condition change/span of chorus tenure), in which the denominator is highly correlated with the dependent variable $\left(\mathbf{R}^{2}=0.90\right)$, would make interpretation of results problematic (Appendix 3).

The effect of foraging success on tenure (Prediction 4) was tested by conducting a feeding experiment. After weighing and marking new males, each was randomly assigned to one of three experimental treatment groups: fed $(N=27)$, sham-fed $(N=27)$ and released $(N=25)$. The released treatment group was a control for the effects of overnight captivity and frogs in this group were returned to the chorus site from which they were taken, immediately following marking. Fed and sham-fed frogs were housed communally overnight until experimental treatment was applied the following afternoon. Bullfrogs in the fed group were force-fed two raw chicken hearts, each implanted with a freeze-dried, nutrient-dusted cricket to ensure the frogs received a nutritionally balanced meal. A male was force-fed by prying open his mouth with a spatula, placing the chicken heart inside and then allowing the frog to close his mouth. The frog was then returned to an individual bucket where he swallowed the food. The sham-fed treatment 
group was a control for the effects of handling during feeding. Sham-fed males were handled in the same way as bullfrogs in the fed treatment group, except that forceps were placed inside the frog's mouth without food for approximately the same amount of time needed to force-feed the fed frogs (University of Guelph Animal Care Committee Animal Utilization Protocol 98R072).

After approximately $80 \%$ of the total population of chorusing male bullfrogs had undergone initial treatment, the experimental treatment was conducted three additional times (on days 18,32 and 44 of the chorusing season). This was done to increase the size of the treatment effect and to touch-up tattoos if necessary. Individual bullfrogs remained in the same treatment group for the duration of the experiment.

Prediction five was examined by comparing the change in body condition of male bullfrogs during temporary absences from chorus tenure.

\section{Analyses}

Mating success data were analyzed to test whether the benefit of longer tenure seen in previous years (MacDonald 1997) was still evident in 1998. Both mean chorus tenure and mean dominant tenure were compared between bullfrogs that were observed to have acquired at least one mate in 1998 and those that were not. Relationships between tenure and the number of observed matings were tested using one-tailed bivariate correlations.

The cost of chorus tenure was established by comparing the mean change in condition (body mass controlling for size) for all individuals of the 1998 chorusing season to zero (no change) using a one-tailed t-test. Relationships between tenure and change in condition were tested using one-tailed bivariate correlations. 
The effect of the feeding experiment on male behaviour was examined by comparing the released and sham-fed treatment groups with respect to the number of nights it took males to return to chorusing activity following processing and whether they returned to the same chorus following processing. I predicted that if the extra handling of the fed and sham-fed treatment groups had a negative effect on the frogs' behaviour then released males would be more likely to resume chorusing faster and at the same chorus following initial capture than sham-fed males.

To test that the random assignment of frogs to treatments had not resulted in substantially different initial characteristics of the frogs in each group, the three treatment groups were compared with respect to body size and initial body condition using one-way ANOVA and the proportions of each experience class (i.e. first year chorusers, second year chorusers and third year chorusers) in each treatment group were compared using a chi-square test.

Final condition and residual condition change were compared among the three treatment groups using one-way ANOVA to examine the effect of the experimental treatments on the body condition of the treatment groups.

Predictions one to four were tested using multiple regression with the three measures of condition as continuous independent variables and feeding status (i.e. fed or unfed) as a categorical independent variable. Two multiple regression analyses were conducted with chorus tenure and then dominant tenure as the dependent variable. Prediction five was tested by comparing the change in bullfrogs' body condition, for all absences (temporary breaks in chorus tenure) of one night or greater, to zero (no change), using one-tailed t-tests.

To test for evidence of directional selection, survivors from 1998 (males that returned to chorus in 1999) were compared to non-survivors (males that did not return) with respect to, 1) initial condition; 2) residual condition change; 3) final condition; 4) the proportional 
representation of the treatment groups (i.e. proportion of survivors that were in the fed treatment group); and 5) the mean change in condition during absences for the 1998 chorusing season using t-tests. The above analyses were conducted between male bullfrogs that were successful breeders in 1998 and males that were not with the exception of final condition. Final condition was compared between successful survivors (males that returned to chorus and mate in 1999) and unsuccessful survivors (males that returned to chorus in 1999, but did not mate) because variation in final condition among males would be more likely to influence male mating success in 1999 than in 1998.

All statistical analyses were carried out using Statistical Package for the Social Sciences (SPSS) Version 8.0 or Statistica Version 5.0. All tests were conducted at the $\alpha=0.05$ level and were two-tailed unless otherwise noted.

\section{Interannual Comparisons of Chorusing Seasons}

A break in the Lake Sasajewrun dam occurred in the spring of 1998, which may have adversely affected the abundance and behaviour of the resident bullfrogs. To determine if 1998 was an anomalous year, characteristics of male bullfrogs (i.e. snout-urostyle length, chorus tenure, dominant tenure, number of choruses visited, etc.) from the 1998 chorusing season were compared with those of males from the four previous years (1994 to 1997). Likewise, characteristics of the 1998 chorusing season (i.e. average nightly number of males, etc.) were compared with two previous years (1996 and 1997) (Appendix 1). 


\section{Alternative Explanations of Abbreviated Tenure}

Age of males has been predicted to influence the amount of resources invested in breeding (Pianka and Parker 1975). Murphy (1994b) suggested that males may be absent from choruses due to mortality or because they have switched chorusing sites and their absence is really sampling error. Therefore, age of male bullfrogs, mortality within choruses and movement among chorusing sites were all examined to assess whether they were important in determining bullfrog chorus tenure during the 1998 chorusing season (Appendix 2).

\section{RESULTS}

The 1998 bullfrog chorusing season on Lake Sasajewun spanned 46 nights from 10 June 1998 to 25 July 1998 and 82 male bullfrogs participated in chorusing activity. The nightly number of males present ranged from 9 to 50 (mean $=28 \pm 9.9$ (s.d.) males) (Figure 3). Chorus tenure varied among bullfrogs (Figure 4a) as did dominant tenure (Figure 4b).

Males that were observed to have acquired at least one mate during the 1998 chorusing season had both higher chorus tenure $(\mathrm{t} 77=2.646, \mathrm{p}<0.011)$ and dominant tenure $(\mathrm{t} z 7=2.810, \mathrm{p}<0.007)$ than males that were not (Figure 5). Mating success (number of observed matings) showed a positive correlation with both chorus tenure $(r=0.272, p<0.016, N=79)$ and dominant tenure $(r=0.294, p<0.009, N=79)$

\section{Energetic Constraint Hypothesis}

Bullfrogs participating in chorus activity during the 1998 season lost condition during their chorus tenure $(t(1), 46=4.313, p<0.001$, mean condition change $=-8.72 \pm 13.86(s . d$.$) g$ [only unfed males, see belowl). Chorus tenure and dominant tenure were negatively correlated with 


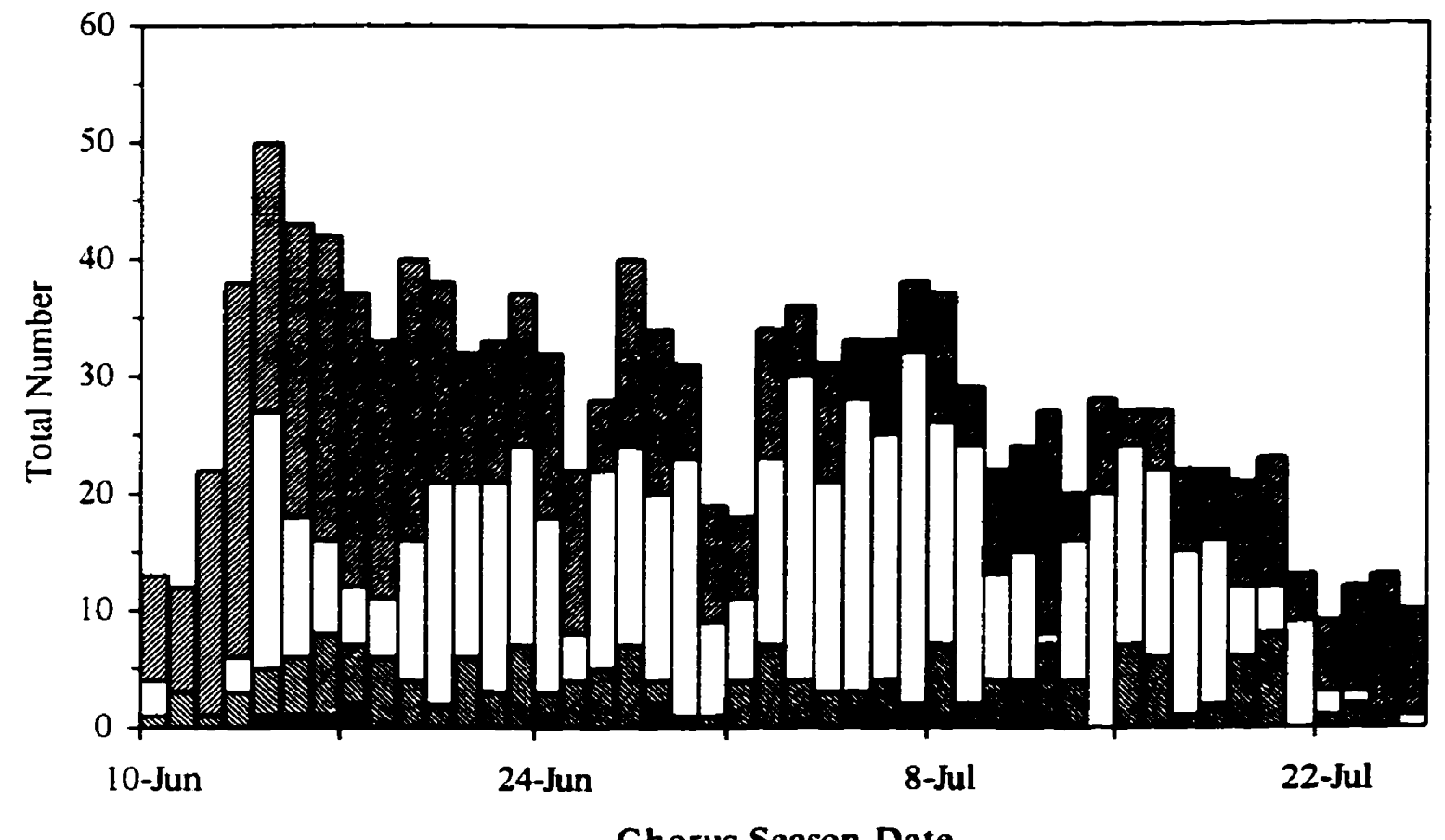

Chorus Season Date

Figure 3. Summary of the 1998 bullfrog chorusing season, Lake Sasajewun, Algonquin Park (higher cross-hatched columns = total males, white columns = dominant males, lower crosshatched columns $=$ females, black columns = matings; mean OSR $=9.3 \pm 6.2(\mathrm{~s}$.d.) males:1 female, median OSR = 6.6 males: 1 female; mean nightly number of males $=27.9 \pm 9.9$ (s.d.) males, median nightly number of males $=28.5$ males). Columns represent true totals and are not stacked. 

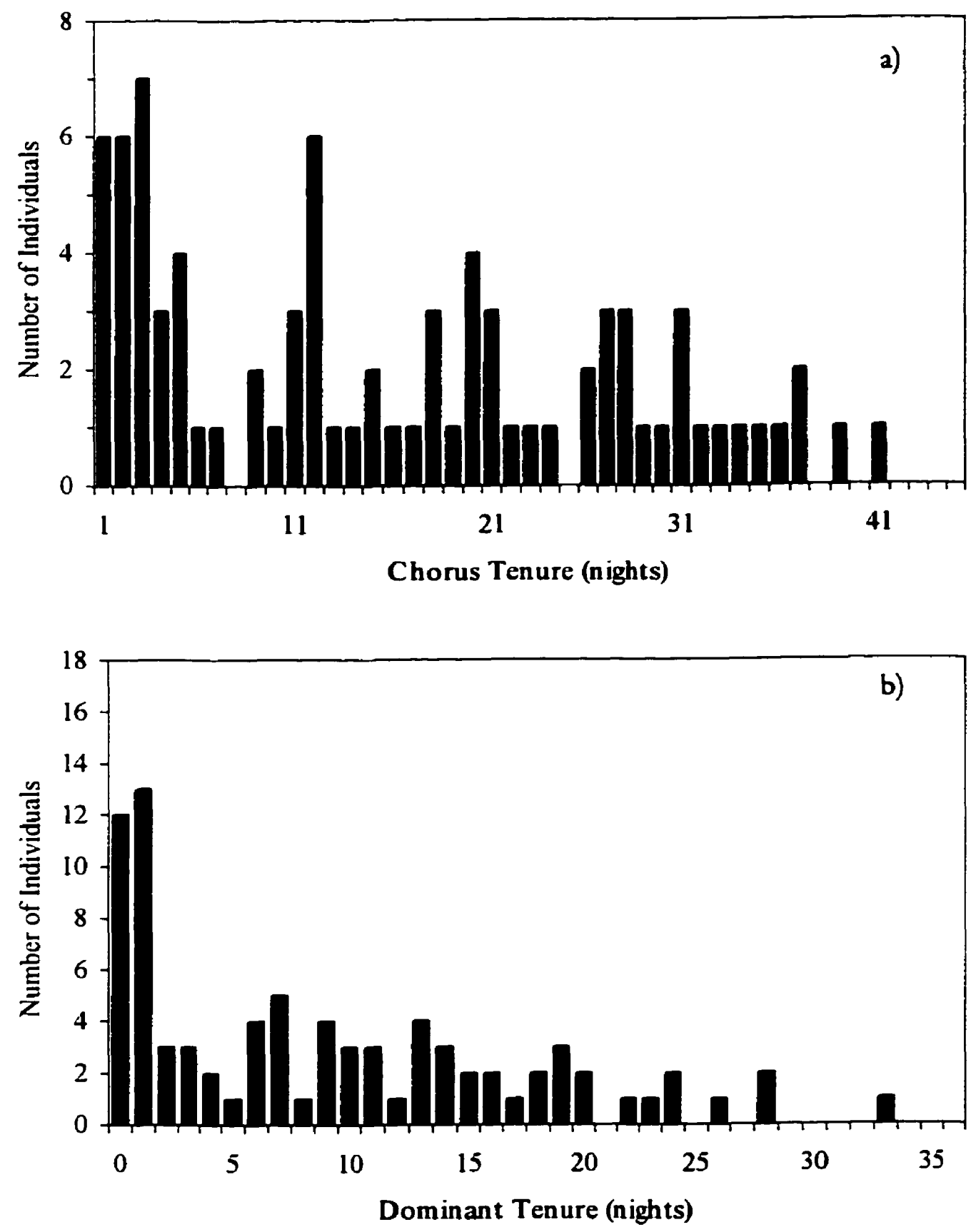

Figure 4. Frequency distribution of bullfrog: a) chorus tenure (mean $=15.67 \pm 11.72$ (s.d.) nights, median $=13.5$ nights, $\mathrm{N}=82$ ) and b) dominant tenure $($ mean $=8.94 \pm 8.38($ s.d.) nights, median $=7$ nights, $\mathbf{N}=\mathbf{8 2}$ ). 


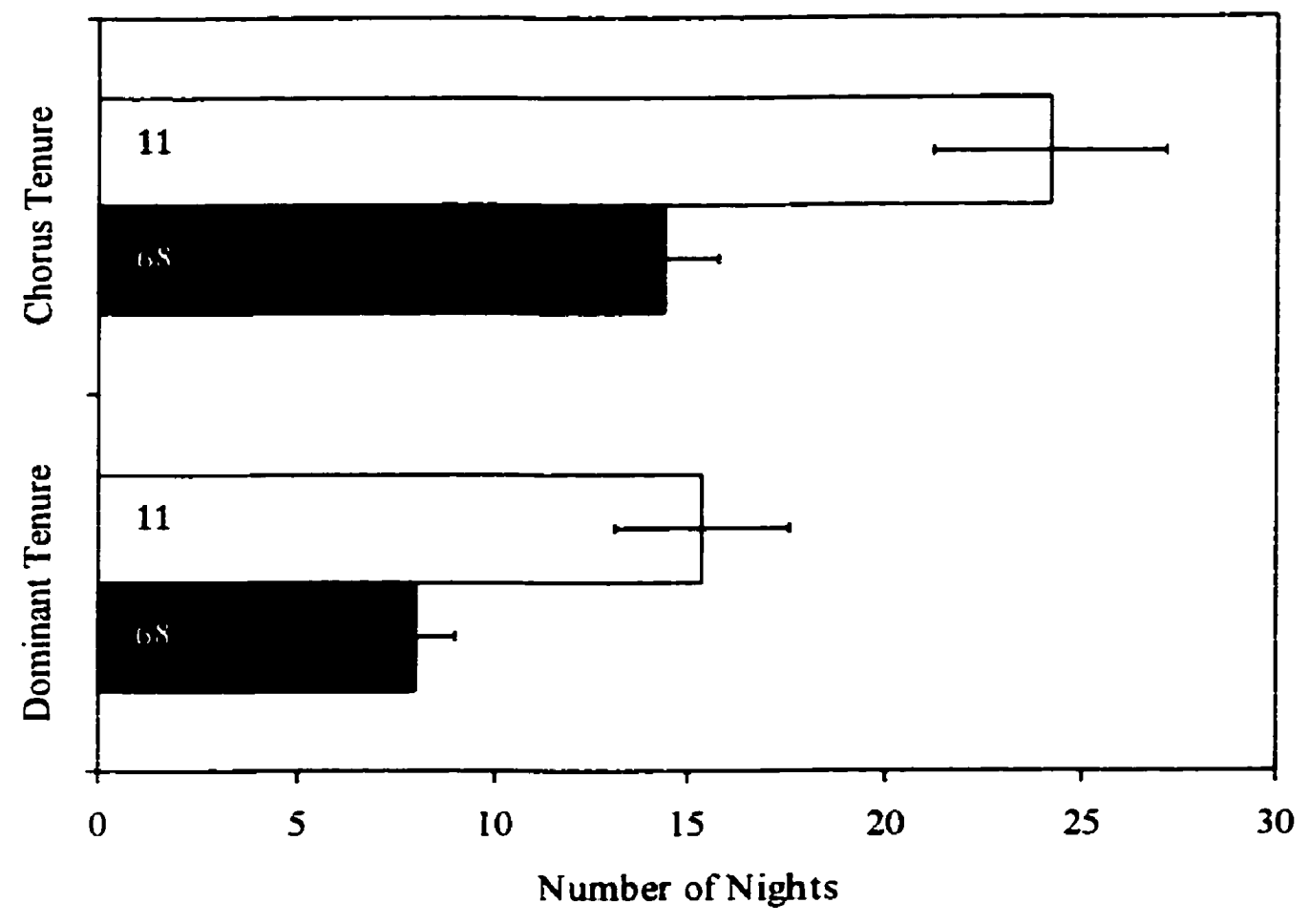

Figure 5. Mean chorus tenure and dominant tenure of successful breeders (light columns) and unsuccessful breeders (dark columns). Bars represent one standard error above and below the mean and numbers within each column are sample sizes. Successful males had both longer chorus tenures $(t r=2.646, p<0.011)$ and dominant tenures $(t \pi=2.810, p<0.007)$ than unsuccessful males. 
change in condition (chorus tenure: $\mathrm{r}=-0.482, \mathrm{p}<0.001, \mathrm{~N}=47$; dominant tenure: $\mathrm{r}=-0.445$, $p<0.002, N=47 ;$ Figure 6).

Released and sham-fed treatment groups did not differ in the number of nights that individual frogs took to resume chorusing activity following their initial capture Mann-Whitney $U=1.580, p<0.115, N=52)$ or in whether frogs returned to the same chorus after initial capture $\left(\chi_{2}^{2}=1.476, \mathrm{p}<0.50, \mathrm{~N}=52\right)$.

The three treatment groups (fed, sham-fed and released) did not differ in terms of size $\left(F_{2.76}=0.433, p<0.651\right)$, initial condition $\left(F_{2.75}=0.866, p<0.426\right)$, or the proportional representation of each of the three experience classes (first year chorusers, second year chorusers and third year chorusers $)\left(\chi^{2}+=5.428, \mathrm{p}<0.25, \mathrm{~N}=79\right)$.

There were differences among groups in final condition $\left(F_{2.69}=7.538, p<0.002\right)$ and residual condition change $\left(F_{2.69}=10.877, p<0.001\right)$. Sham-fed and released frogs were not different in their final condition $(t+5=0.108, p<0.915)$ or residual condition change $(t+5=0.647$, $p<0.522$ ) and so were pooled together as unfed frogs. Fed frogs had better final condition than unfed frogs (tro $=3.908, p<0.001$, Figure $7 a$ ), and fed frogs had better (i.e. more positive) residual condition change than unfed frogs $(t(1), 70=4.636, p<0.001$, Figure $7 b)$.

In multiple regression, the four independent variables explained $83.8 \%$ ( $82.8 \%$ adjusted) of the variation in chorus tenure $\left(r=0.915, F_{4,67}=5.220, p<0.002\right.$, Table 2$)$ and explained $66.6 \%$ $(64.6 \%$ adjusted $)$ of the variation in dominant tenure $\left(r=0.816, F_{4,6}=3.933, p<0.007\right.$, Table 3$)$. The standardized regression coefficients of all four predictors were highly significant for both multiple regression models and in the predicted direction. Other things being equal, males with longer tenures had, on average, 1) better initial condition; 2) poorer final condition; and 3) higher residual condition change than males with shorter tenures; also, 4) fed males had longer tenure 


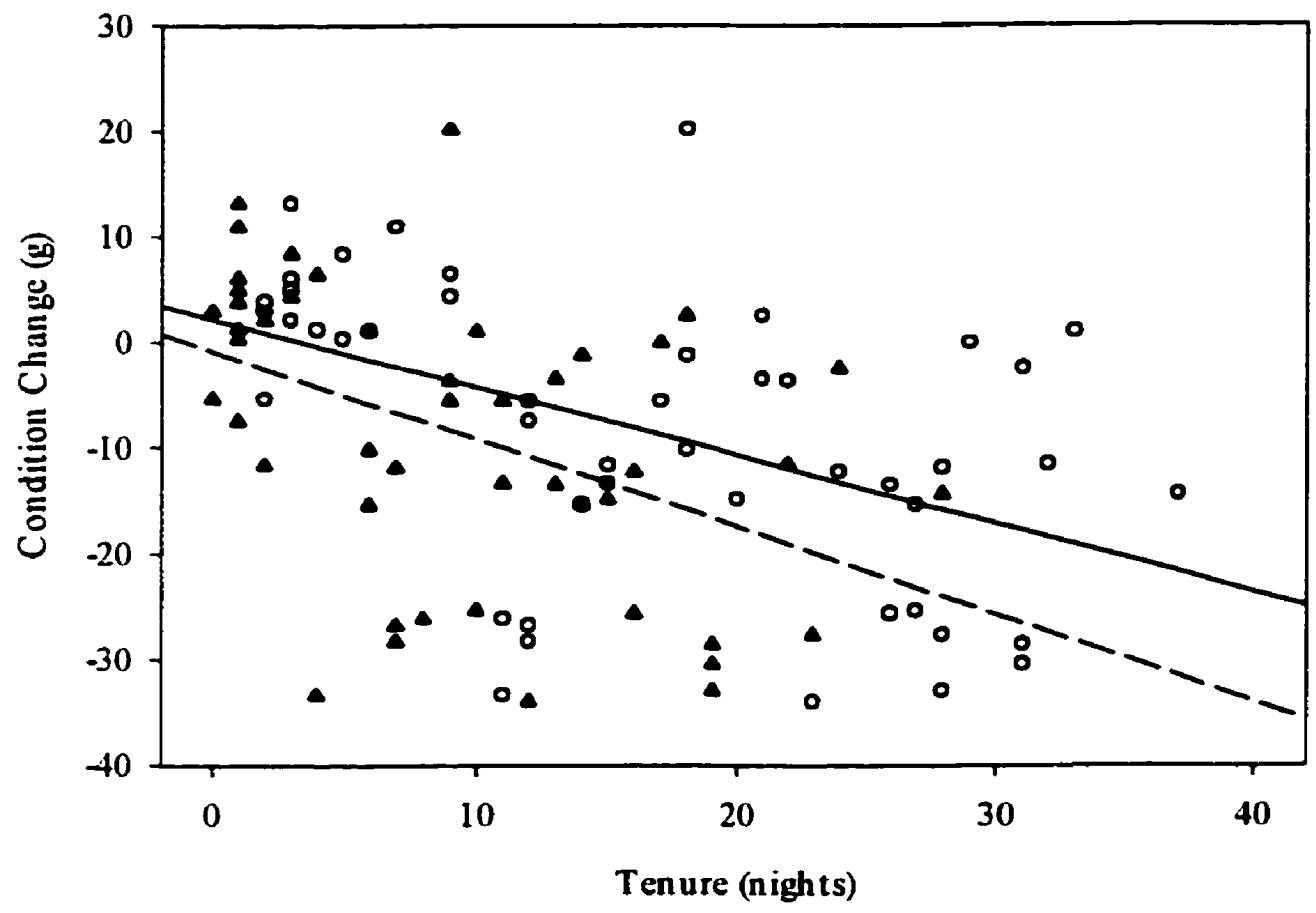

Figure 6. Plot of condition change versus chorus tenure (hollow circles and solid line) and dominant tenure (solid triangles and dashed line). Condition change was negatively related to both chorus tenure $(r=-0.482, p<0.001, N=47)$ and dominant tenure $(r=-0.445, p<0.002$, $N=47$ ) (see Figure 2a). 

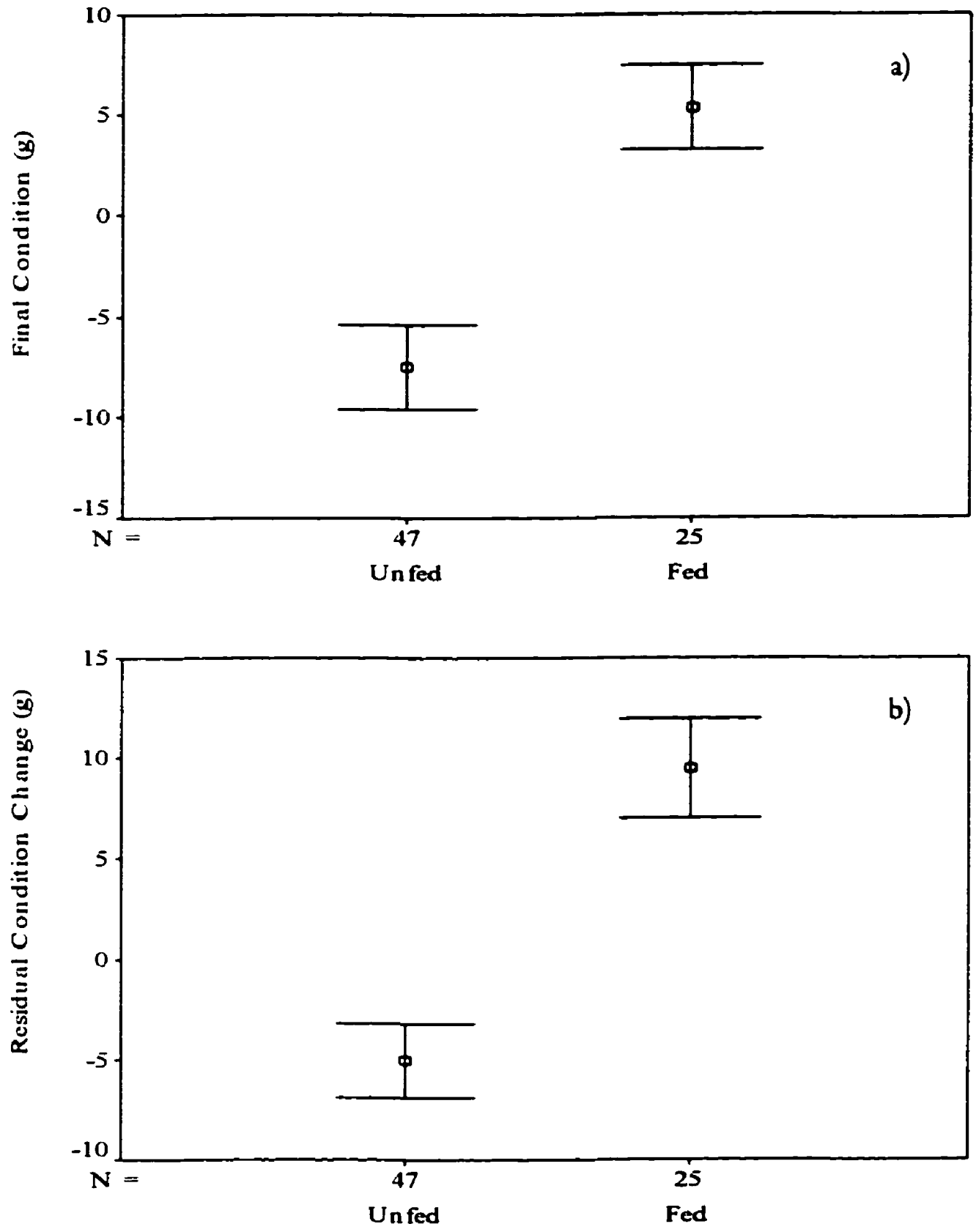

Figure 7. Error bar plots of: a) final condition and b) residual condition change for fed and unfed male bullfrogs. Fed bullfrogs had higher final condition $(t(1), 0=3.908, p<0.001)$ and higher residual condition change $(t(t) .70=4.636, p<0.001)$ than unfed frogs. Sample sizes are listed along the $\mathbf{x}$-axis. 
Table 2. Summary of the results of the multiple regression of chorus tenure on initial condition, final condition, residual condition change and feeding status $\left(r=0.915, F_{4,6}=5.220, p<0.002\right)$. The first four columns of numbers are a matrix of one-tailed Pearson correlation coefficients $(r)$. B is the unstandardized regression coefficient, $\beta$ is the standardized regression coefficient, pr is the partial correlation coefficient, $\mathrm{sr}$ is the semipartial correlation coefficient and Tol. is the tolerance value.

\begin{tabular}{|c|c|c|c|c|c|c|c|c|c|}
\hline Variables & $\begin{array}{l}\text { Chorus } \\
\text { Tenure }\end{array}$ & IC & FC & RCC & B & $\beta$ & pr & sr & Tol. \\
\hline \multirow{7}{*}{$\begin{array}{l}\text { Initial Condition (IC) } \\
\text { Final Condition (FC) } \\
\text { Residual Condition Change (RCC) } \\
\text { Feeding Status ( } 0 \text { - Unfed, } 1 \text { - Fed) }\end{array}$} & -0.063 & & & & 2.220 & $1.716^{\circ *}$ & 0.884 & 0.761 & 0.197 \\
\hline & $-0.340^{\circ-1}$ & $0.242^{\circ}$ & & & -2.254 & $-2.854^{4 \prime \prime}$ & $\begin{array}{c}-0.914 \\
\end{array}$ & -0.911 & 0.100 \\
\hline & -0.014 & $-0.388^{\prime \prime}$ & $0.750^{* 1}$ & & 2.154 & $2.707^{* *}$ & 0.898 & 0.822 & 0.092 \\
\hline & 0.036 & -0.156 & $0.423^{* *}$ & $0.485^{* *}$ & 4.959 & $0.208^{\prime \prime}$ & 0.408 & 0.180 & 0.749 \\
\hline & & & & Intercept & 8.120 & & & & \\
\hline & & & & $\mathbf{R}^{2}$ & 0.838 & & & & \\
\hline & & & & djusted $R^{2}$ & 0.828 & & & & \\
\hline
\end{tabular}


Table 3. Summary of the results of the multiple regression of dominant tenure on initial condition, final condition, residual condition change and feeding status $\left(r=0.816, F_{4,67}=3.933, p<0.007\right)$. The first four columns of numbers are a matrix of one-tailed Pearson correlation coefficients $(r)$. B is the unstandardized regression coefficient, $\beta$ is the standardized regression coefficient, $p r$ is the partial correlation coefficient, sr is the semipartial correlation coefficient and Tol. is the tolerance value.

\begin{tabular}{|c|c|c|c|c|c|c|c|c|c|}
\hline Variables & $\begin{array}{l}\text { Dominant } \\
\text { Tenure }\end{array}$ & IC & FC & RCC & B & $\beta$ & $\mathrm{pr}$ & sr & Tol. \\
\hline Initial Condition (IC) & 0.060 & & & & 1.700 & $1.793^{*+}$ & 0.784 & 0.729 & 0.197 \\
\hline Final Condition (FC) & $-0.255^{\circ}$ & $0.242^{*}$ & & & -1.607 & $-2.796^{* *}$ & -0.813 & .0 .808 & 0.100 \\
\hline Residual Condition Change (RCC) & -0.065 & -0.388 & $0.750^{\circ *}$ & & 1.536 & $2.635^{* *}$ & 0.782 & 0.726 & 0.092 \\
\hline Feeding Status $(0-$ Unfed, 1 - Fed) & 0.066 & -0.156 & $0.423^{4 *}$ & $\begin{array}{c}0.485{ }^{*} \\
\text { Intercept }\end{array}$ & $\begin{array}{c}4.240 \\
2.717\end{array}$ & $0.243^{* *}$ & 0.341 & 0.210 & 0.749 \\
\hline & & & & $\mathbf{R}^{2}$ & 0.666 & & & & \\
\hline & & & & djusted $\mathbf{R}^{2}$ & 0.646 & & & & \\
\hline
\end{tabular}

\footnotetext{
$p<0.05$

$" p<0.01$
} 
than unfed males (chorus tenure: Table 2, Figure 8; dominant tenure: Table 3, Figure 9).

However, all four independent variables were highly correlated with each other and tolerance values for each of the independent variables were low (Tables 2 and 3). Low tolerance values indicated that there was a problem with multicollinearity, which may have resulted in unstable estimates of multiple regression coefficients (Tabachnick and Fidell 1996). I chose to use ridge regression to deal with high correlation among the predictors.

In ridge regression, the four predictors explained $29.1 \%$ ( $24.9 \%$ adjusted) of the variation in chorus tenure $\left(r=0.540, F_{4.67}=6.881, p<0.001\right.$, Table 4$)$ and explained $22.5 \%(17.9 \%$ adjusted) of the variation in dominant tenure $\left(r=0.474, F_{4,6}=4.858, p<0.002\right.$, Table 5). Tolerance values for each of the independent variables were several times higher than in the standard multiple regressions (Tables 4 and 5). The standardized regression coefficients ( $\beta s$ ) for initial condition, final condition and residual condition change were significant and in the predicted direction for both chorus tenure (Table 4) and dominant tenure (Table 5). However, $\beta$ for feeding status was not significant for either chorus tenure (Table 4) or dominant tenure (Table 5). Therefore, males with longer tenures, other things being equal, had, on average, 1) better initial condition; 2) poorer final condition; and 3) higher residual condition change than males with shorter tenures, but, 4) fed males did not have significantly longer tenure than unfed males.

Mean condition change during temporary absences was not significantly positive for any length of absence or for all absences combined (Table 6).

There were no significant differences between survivors and non-survivors for any of the variables (Table 7). However, successful male bullfrogs had higher initial condition and lower residual condition change (i.e. successful male bullfrogs lost more condition than predicted for the 

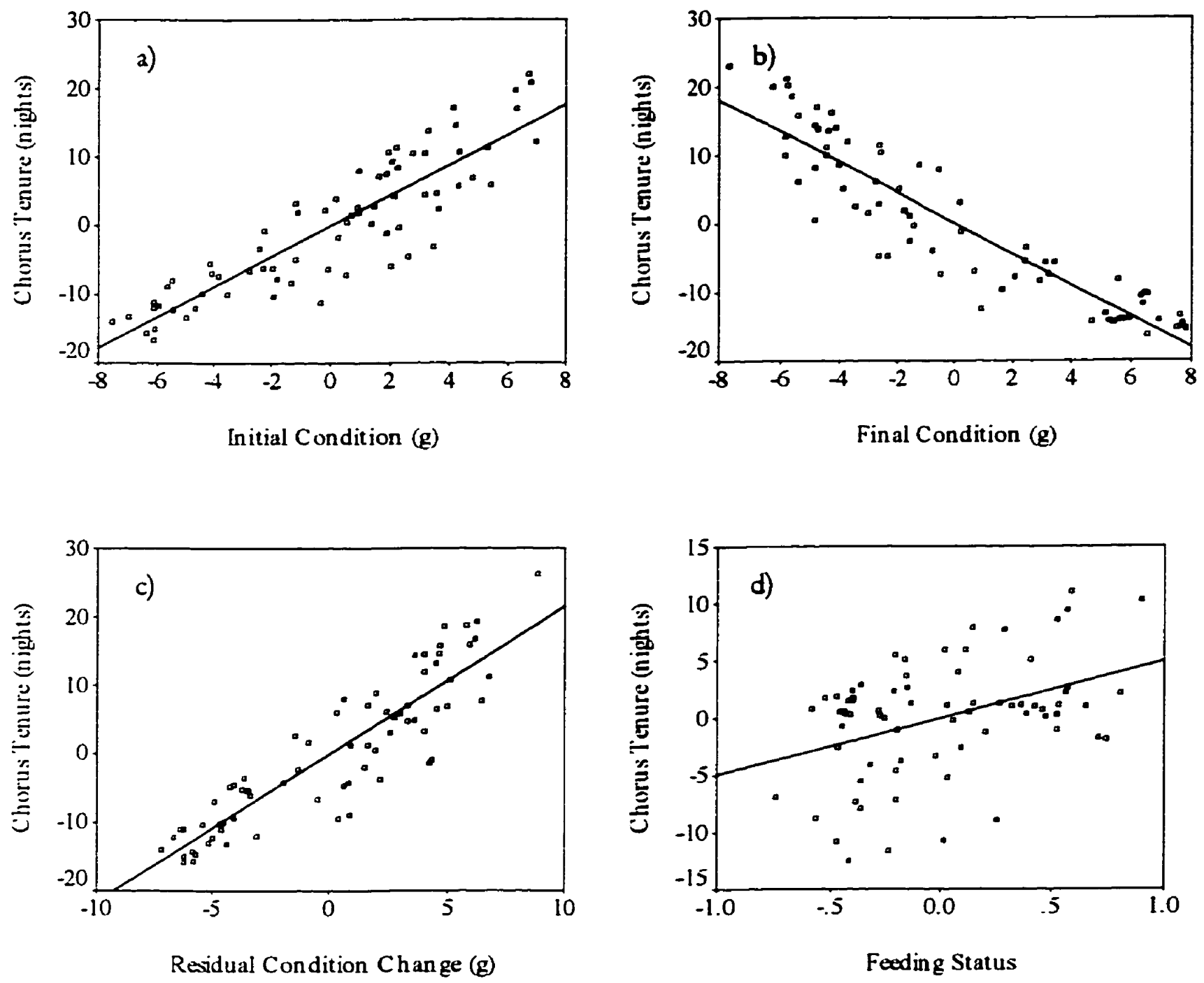

Figure 8. Partial regression plots of chorus tenure residuals versus the residuals of: $a$ ) initial condition $\left(R^{2}=0.78\right)$, b) final condition $\left(R^{2}=0.84\right)$, c) residual condition change $\left(R^{2}=0.81\right)$ and d) feeding status $\left(R^{2}=0.17\right)$, corresponding to Figures $2 b$ to $2 f$ respectively. 

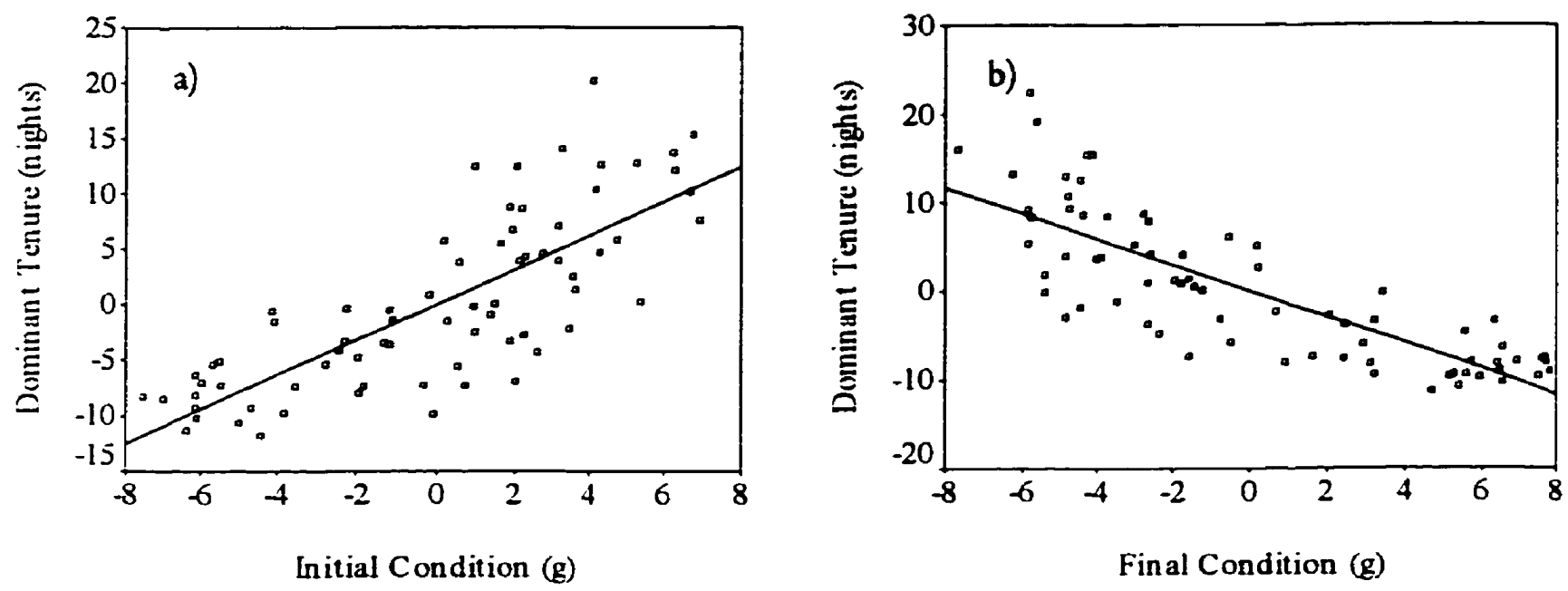

Final Condition (g)
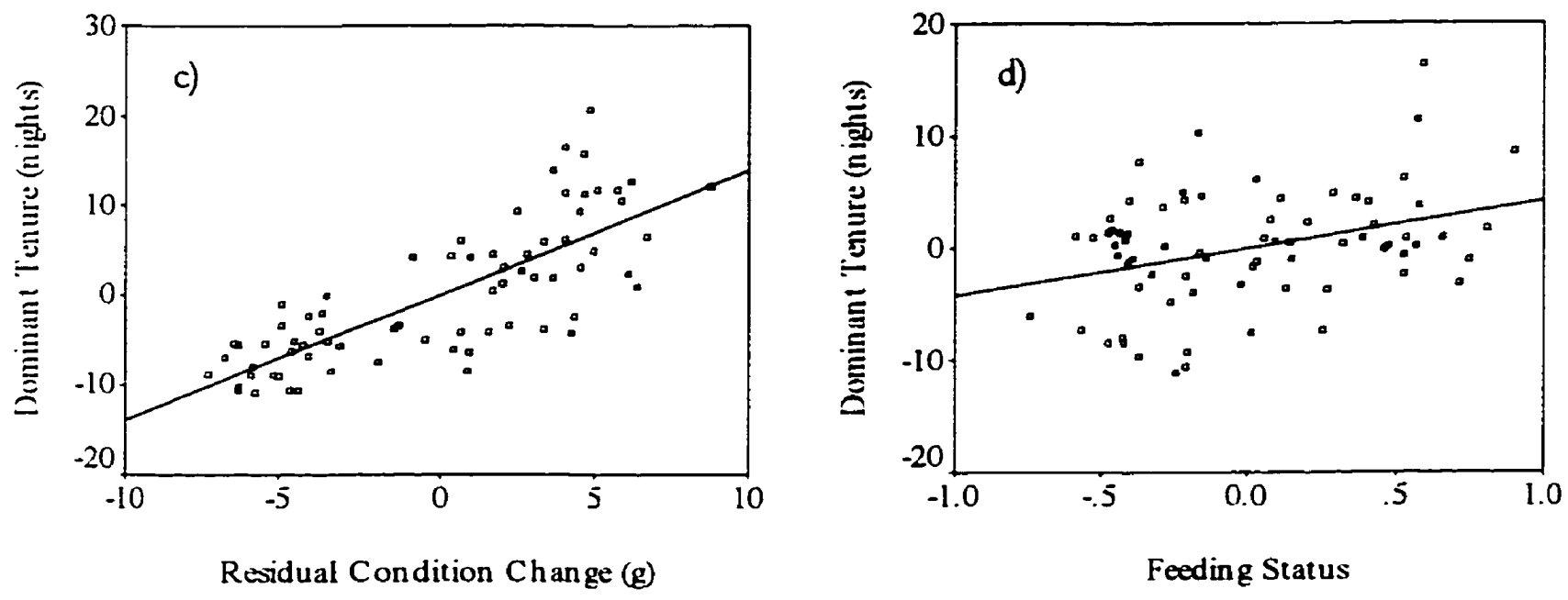

Figure 9. Partial regression plots of dominant tenure residuals versus the residuals of: a) initial condition $\left.\left(R^{2}=0.61\right), b\right)$ final condition $\left(R^{2}=0.66\right)$, c) residual condition change $\left(R^{2}=0.61\right)$ and d) feeding status $\left(R^{2}=0.12\right)$, corresponding to Figures $2 b$ to $2 f$ respectively. 


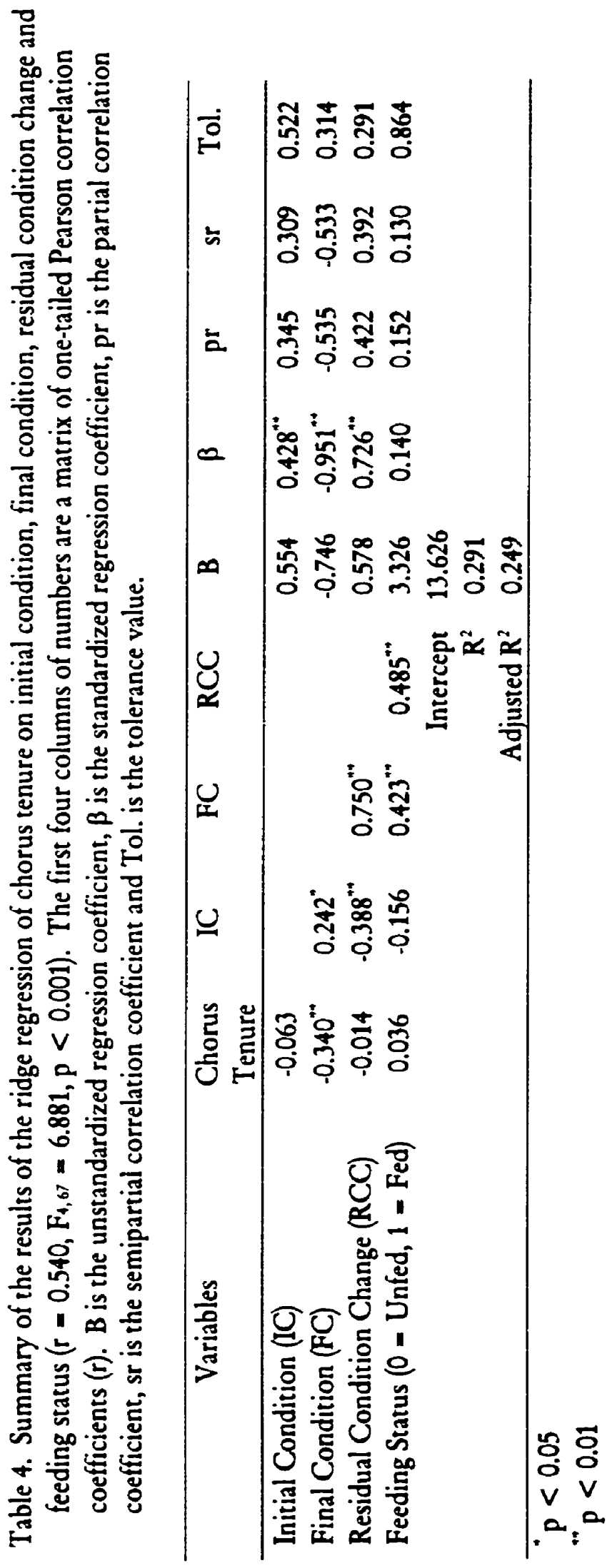


Table 5. Summary of the results of the ridge regression of dominant tenure on initial condition, final condition, residual condition change and feeding status $\left(r=0.474, F_{4,67}=4.858, p<0.002\right)$. The first four columns of numbers are a matrix of one-tailed Pearson correlation coefficients $(r)$. B is the unstandardized regression coefficient, $\beta$ is the standardized regression coefficient, pr is the partial correlation coefficient, $s r$ is the semipartial correlation coefficient and Tol. is the tolerance value.

\begin{tabular}{|c|c|c|c|c|c|c|c|c|c|}
\hline Variables & $\begin{array}{c}\text { Dominant } \\
\text { Tenure }\end{array}$ & IC & FC & $\mathrm{RCC}$ & B & $\beta$ & $\mathrm{pr}$ & sr & Tol. \\
\hline Initial Condition (IC) & 0.060 & & & & 0.454 & $0.479^{-4+}$ & 0.366 & 0.346 & 0.522 \\
\hline Final Condition (FC) & $-0.255^{\star}$ & $0.242^{+}$ & & & -0.474 & $-0.825^{* *}$ & -0.464 & -0.462 & 0.314 \\
\hline Residual Condition Change (RCC) & -0.065 & $-0.388^{* 4}$ & $0.750^{* 4}$ & & 0.360 & $0.618^{+1+1}$ & 0.354 & 0.333 & 0.291 \\
\hline \multirow[t]{4}{*}{ Feeding Status $(0-$ Unfed, $1=$ Fed $)$} & 0.066 & -0.156 & $0.423^{4 *}$ & $0.485^{4 *}$ & 3.026 & 0.173 & 0.180 & 0.161 & 0.864 \\
\hline & & & & Intercept & 7.259 & & & & \\
\hline & & & & $\mathbf{R}^{2}$ & 0.225 & & & & \\
\hline & & & & djusted $\mathbf{R}^{2}$ & 0.179 & & & & \\
\hline
\end{tabular}


Table 6. Summary of male bullfrog temporary absences during the 1998 chorusing season. Mean condition changes, for absences of a given duration, were compared to zero in order to test whether males were leaving to recoup lost condition. No mean condition change for any absence duration was significantly greater than zero.

\begin{tabular}{cccccccc}
\hline $\begin{array}{c}\text { Length of } \\
\text { Absence (nights) }\end{array}$ & $\begin{array}{c}\text { Total Number } \\
\text { of Absences }\end{array}$ & $\begin{array}{c}\text { Number of Bullfrogs } \\
\text { for each Absence }\end{array}$ & $\begin{array}{c}\text { Cumulative Number of } \\
\text { Bullfrogs for each Absence }\end{array}$ & $\begin{array}{c}\text { Mean condition } \\
\text { change (g) }\end{array}$ & SE & N & Sig. \\
\hline 1 & 140 & 54 & 54 & 0.293 & 0.637 & 128 & n.s. \\
2 & 50 & 34 & 62 & 0.933 & 1.054 & 46 & n.s. \\
3 & 28 & 22 & 63 & 0.852 & 1.665 & 25 & n.s. \\
4 & 16 & 13 & 63 & -1.788 & 2.261 & 16 & n.s. \\
5 & 7 & 7 & 64 & 1.571 & 4.615 & 7 & n.s. \\
6 & 1 & 1 & 64 & -3.0 & & 1 & \\
$\infty$ & 3 & 3 & 64 & 0.233 & 11.560 & 3 & n.s. \\
7 & 2 & 2 & 64 & 8.8 & & 1 & \\
8 & 3 & 3 & 64 & 1.600 & 1.900 & 2 & n.s. \\
9 & 1 & 1 & 64 & -7.9 & & 1 & \\
10 & 1 & 1 & 64 & & & 0 & \\
11 & 2 & 2 & 64 & -2.800 & 1.100 & 2 & n.s. \\
15 & 1 & 1 & 64 & -1.0 & & 1 & \\
17 & 1 & 1 & 64 & 6.8 & & 1 & \\
18 & 1 & 1 & 64 & 11.7 & & 1 & \\
20 & 257 & & 64 & 0.416 & 0.503 & 235 & n.s. \\
\hline
\end{tabular}


Table 7. Comparisons of initial condition, final condition, residual condition change, feeding status and condition change during absences, between male bullfrogs that survived the 1998 chorusing season and male bullfrogs that did not survive the 1998 chorusing season.

\begin{tabular}{lccccc}
\hline Variable & Survive? & Mean & SE & N & Sig. \\
\hline Initial Condition (g) & Yes & 1.28 & 2.65 & 14 & n.s. \\
& No & -0.28 & 1.04 & 64 & \\
\hline Final Condition (g) & Yes & -4.01 & 3.51 & 14 & n.s. \\
& No & -2.06 & 2.07 & 59 & \\
\hline Residual Condition & Yes & 1.59 & 3.29 & 14 & n.s. \\
Change (g) & No & -0.38 & 1.95 & 58 & \\
\hline Feeding Status & Yes & $29 \%(1)$ & & $4 / 14$ & n.s. \\
(1= fed bullfrogs) & No & $35 \%(1)$ & & $23 / 65$ & \\
\hline Condition Change & Yes & 0.22 & 0.83 & 83 & n.s. \\
During Absences (g) & No & 0.52 & 0.63 & 152 & \\
\hline
\end{tabular}

${ }^{*} p<0.05$

${ }^{* *} p<0.01$ 
Table 8. Comparisons of initial condition, final condition, residual condition change, feeding status and condition change during absences, between male bullfrogs that were successful breeders and males that were not successful breeders.

\begin{tabular}{lcccccc}
\hline Variable & Successful? & Year & Mean & SE & N & Sig. \\
\hline Initial Condition (g) & Yes & 1998 & 7.89 & 2.05 & 11 & $* *$ \\
& No & 1998 & -1.30 & 1.00 & 67 & \\
\hline Final Condition (g) & Yes & 1999 & 0.76 & & 1 & n.s. \\
& No & 1999 & -4.37 & 3.78 & 13 & \\
\hline Residual Condition & Yes & 1998 & -10.43 & 3.75 & 11 & $* *$ \\
Change (g) & No & 1998 & -1.88 & 1.79 & 61 & \\
\hline Feeding Status & Yes & 1998 & $27 \%(1)$ & & $3 / 11$ & n.s. \\
(1= fed bullfrogs) & No & 1998 & $35 \%(1)$ & & $24 / 68$ & \\
\hline Condition Change & Yes & 1998 & -0.33 & 0.87 & 38 & n.s. \\
During Absences (g) & No & 1998 & 0.56 & 0.58 & 197 & \\
\hline
\end{tabular}

${ }^{*} \mathrm{p}<0.05$

${ }^{* *} p<0.01$ 
amount of time spent participating in chorus activity) than unsuccessful males (Table 8). Males that survived to 1999 and were successtul were not in significantly different condition at the end of 1998 chorus tenure than unsuccessful survivors (i.e. increased final condition did not confer a mating success advantage on males the following year) (Table 8).

\section{DISCUSSION}

As in previous years (MacDonald 1997) and in other species of anurans (reviewed in Table 1), male bullfrogs with both longer chorus tenures and longer dominant tenures acquired more mates. This is evidence that sexual selection, through endurance rivalry, may be acting on male traits that would increase male attendance at choruses (Andersson 1994). However, the prevalence of abbreviated tenure in male anurans (reviewed in Murphy 1992, MacDonald 1997, my study) indicates that there are limits to the length of time a male is willing or able to devote to breeding site attendance.

\section{Energetic Constraint Hypothesis}

Endurance rivalry should favour greater energetic efficiency among males attending choruses (Andersson 1994). However, before this can be tested, chorus tenure must be shown to be constrained by energetic condition. Energetic constraint of tenure presupposes that tenure is energetically costly for male anurans (the precondition of my energetic constraint hypothesis, see Figure 2a). As in other studies (e.g. Wells 1978, Arak 1983a, Robertson 1986, Given 1988a, Ryser 1989, Murphy 19946, MacDonald 1997), tenure was costly for male bullfrogs. Males lost body condition during the chorusing season and that condition loss correlated with both chorus tenure 
and dominant tenure. With this precondition satisfied, the energetic constraint hypothesis was tested.

My study showed that chorus tenure and dominant tenure in bullfrogs were constrained by energetic condition. When entered into a ridge regression model, initial condition, final condition, residual condition change and feeding status explained $24.9 \%$ of the variation in chorus tenure and $17.9 \%$ of the variation in dominant tenure. Altogether, three of five predictions of the energetic constraint hypothesis were supported. Males that, started their tenures in better condition (Prediction 1); allowed their condition to decline more (Prediction 2); and lost less condition than expected (Prediction 3), had longer tenures than males that did not. However, fed males did not have longer tenures than unfed males (Prediction 4) and males did not increase their condition during absences from chorusing activity (Prediction 5). Abbreviated tenure in male bullfrogs seems to be the result of constraint on male energetic condition.

MacDonald (1997) also found that initial condition was positively related to tenure in male bullfrogs. Better initial condition may have been the result of increased foraging success before chorus tenure began or better over-wintering condition (indistinguishable in my study), or males in better initial condition may simply have started tenure earlier than males in poorer initial condition. If the latter was the case, then there should have been a negative relationship between the date on which males started their chorus attendance and their condition on that day. There was no significant correlation between initial date and initial condition $(r=0.016, p<0.890$, $N=78$ )

Initial condition had no effect on survival of males to 1999 . However, males that were successful breeders in 1998 were in better initial condition than unsuccessful breeders. This result, in concert with the positive relationship between tenure and initial condition, suggests that there 
was direct sexual selection favouring males with increased body condition at the start of chorus tenure. However, it is not clear by which mechanism sexual selection may have acted. Male body condition is likely related to male quality, and as such higher initial condition is probably preferred by female bullfrogs, either because of direct genetic benefits or because of increased fertilization rates (e.g. Ryan 1983, 1985). High energetic condition is also probably helpful in direct male-male aggressive encounters (Arak 1983a). The relative importance of each of these mechanisms is unclear and possibly unresolveable; although the direct, positive relationship between tenure and initial condition is evidence that endurance rivalry was an important selective force.

Residual condition change is a measure of energetic efficiency; males with more positive residual condition change have lost less condition than expected given the timespan over which they have chorused, i.e. they have been more energetically efficient. As predicted (Andersson 1994, energetic constraint hypothesis), males that were more energetically efficient chorused for longer. However, male bullfrogs that were successful breeders in 1998 were less efficient (i.e. residual condition change was more negative) than unsuccessful breeders (Table 7). It appears as though selection operated in opposing directions. Males that engage in energetically costly displays, such as frequent bouts of wrestling or high call rates, may be preferred by females at the expense of the energetic efficiency of those activities (Zahavi 1975). One usually thinks of sexual selection acting to develop some male trait, such as song in anurans (reviewed in Searcy and Andersson 1986), and of natural selection acting to mitigate the survival costs incurred by such traits. However, in my study, endurance rivalry acted to increase male energetic efficiency and female choice, or some other mechanism of sexual selection (Andersson 1994), may have operated to decrease male energetic efficiency. 
It may not be immediately apparent how final energetic condition can constrain tenure; however, it may do so in two ways. Firstly, there may be a lower threshold of body condition below which males cannot continue to participate in breeding activity (i.e. a current cost). If this is the case, then males should always return to the chorus after a temporary absence in better condition than when they left (Bevier 1997). Following absences of any length, male bullfrogs returned to chorusing activity in no better condition than when they left (Table 6). Even when analysis was restricted to absences of greater than or equal to five nights, mean condition change was not positive $($ mean $=-0.108 \pm 9.79$ (s.d.)g, $\mathrm{p}<0.948$ ). Therefore, males did not leave because their energetic condition was too low to allow them to continue to participate in chorus activity, and they did not seem to be foraging while they were away from the chorus. However, the question as to why male bullfrogs temporarily left chorus activity is still open.

Temporary absences have been reported for other species (Scinax boulengeri and S. rubra, Bevier 1997; Physalaemus pustulosus, Green 1990; Hyla gratiosa, Murphy 1994a). Males of Scinax boulengeri showed a positive relationship between the length of absence and change in body mass, indicating that males may have left to recoup energy lost during chorusing activity (Bevier 1997). Male bullfrog body condition may interact with a number of other variables such as: environmental conditions (temperature, wind velocity, etc.), the OSR, risk of predation, individual age (see Appendix 2) and overall vigor to cause some individuals to leave and others to remain active. In the future it would be interesting to use radiotelemetry to determine unequivocally whether males do take breaks during their chorus tenure. Radiotelemetry would also answer questions about where males go, during absences from chorus tenure; during the daytime; after the chorusing season; and during hibernation, and would provide more information about the extent of movement among choruses and lakes. 
Secondly, decreased body condition may be costly in terms of over-winter survival and future reproduction (i.e. a future cost). If this is true, then males that survived the following winter should have a higher mean body condition at the end of their chorus tenures than males that did not survive, and/or, among over-winter survivors, final condition in 1998 should be positively related to initial condition in 1999. Males that survived to the following year did not have significantly higher final condition than males that did not survive (Table 7). For bullfrogs that did survive to 1999 , there was a significant positive correlation between final condition in 1998 and initial condition in 1999 (one-tailed $\mathrm{r}=0.456, \mathrm{p}<0.039, \mathrm{~N}=16$ ). This means that bullfrogs that ended their 1998 chorus tenures in poor condition, paid an energetic cost in terms of poorer condition at the start of the 1999 season, relative to males that finished 1998 in better condition. Given the positive relationship between initial condition and tenure shown in 1998, it appears that there could be a tradeoff between current and future chorusing effort. Data from 1998 failed to show a relationship among chorusing effort, age and mortality (Appendix 2) that would explain why some males might have low residual reproductive value (Pianka and Parker 1975). However, previous work (MacDonald 1997) suggests that bullfrogs adopt age-specific tenure tactics.

Although the feeding experiment increased male body condition (Figure 7), it did not have a significant effect on the chorus tenure or dominant tenure of the fed treatment group (mean difference: chorus tenure $=1.17 \pm 2.82(\mathrm{SE})$ nights, dominant tenure $=1.29 \pm 2.01(\mathrm{SE})$ nights) . Assignment of individuals to treatment groups did not result in biased initial characteristics of each group and the feeding experiment itself did not introduce experimental bias into the results. Previous feeding experiments have shown mixed results in causing an increase in chorus tenure. Male barking treefrogs significantly increased their chorus tenures when fed (Murphy 1994b). 
However, male túngara frogs showed no significant differences between fed and starved males in chorus tenure, call rate, or call complexity (Green 1990). Per meal, bullfrogs were fed approximately $0.87 \mathrm{kj} / \mathrm{g}$ body mass (average sized male bullfrog $=108.3 \mathrm{~g}$ ) compared to $0.50 \mathrm{kj} / \mathrm{g}$ body mass/meal for barking treefrogs (calculated from Murphy 19946) and $0.41 \mathrm{kj} / \mathrm{g}$ body mass/meal for túngara frogs (calculated from Green 1990). However, instead of increasing the number of nights spent chorusing, fed male bullfrogs could have increased the amount of time that they chorused within a night and/or their call rate. These finer-scale measures of bullfrog chorusing effort have not been gathered for this study system in the past and may provide very different insights into male bullfrog reproductive effort than chorus tenure and dominant tenure. Energetic constraint at one scale of chorusing effort does not preclude or necessitate energetic constraint at a different scale. For example, chorus tenure was significantly increased when male barking treefrogs were fed (Murphy 1994b), but feeding had no effect on the amount of time males spent in the chorus each night (Murphy 1999).

\section{Interannual Comparisons of Chorusing Seasons}

Bullfrog chorus behaviour in 1998 was not consistently different from previous years in which chorus behaviour was measured. Therefore, there was no evidence to suggest that the dam break of 1998 adversely affected the population of chorusing bullfrogs and the results of my study can be used to draw general conclusions about bullfrog chorus behaviour (Appendix 1).

\section{Alternative Explanations of Abbreviated Tenure}

Contrary to previous years, there was no evidence to suggest that male bullfrogs were adopting age-specific tenure tactics. Mortality of male bullfrogs within the chorusing season may 
be an important factor in determining when males end their chorus tenures; however, it cannot explain the high degree of discontinuity in chorus attendance observed in my study and others. Movement between Lake Sasajewun and other bodies of water did not explain variation in chorus tenure as male bullfrogs showed high chorus site fidelity (Appendix 2).

\section{LTIERATURE CITED}

Andersson, M. 1994. Sexual Selection. Princeton University Press, Princeton, New Jersey. Andersson, M. and Y. Iwasa. 1996. Sexual selection. Trends in Ecology and Evolution 11: 53-58. Arak, A. 1983a. Male-male competition and mate choice in anuran amphibians. Chapter 8 in Mate Choice. P. Bateson (ed.) Cambridge University Press, Cambridge.

Arak, A. 1983b. Sexual selection by male-male competition in natterjack toad choruses. Nature 306: 261-262.

Arak, A. 1988. Female mate selection in the natterjack toad: active choice or passive attraction? Behavioral Ecology and Sociobiology 22: 317-328.

Bevier, C.R. 1997. Breeding activity and chorus tenure of two neotropical hylid frogs. Herpetologica 53: 297-311.

Blair, W.F. 1960. A breeding population of the Mexican toad (Bufo valliceps) in relation to its environment. Ecology 41: 165-174.

Brown, L.J. 1997. An evaluation of some marking and trapping techniques currently used in the study of anuran population dynamics. Journal of Herpetology $31: 410-419$.

Cherry, M.I. 1993. Sexual selection in the raucous toad, Bufo rangeri. Animal Behaviour 45: 359373. 
Conant, R. and J.T. Collins. 1998. A Field Guide to Reptiles and Amphibians: Eastern and Central North America. Houghton Mifflin, Boston, Massachusetts.

Davies, N.B. and T.R. Halliday. 1979. Competitive mate searching in male common toads, Bufo bufo. Animal Behaviour 27: 1253-1267.

Denton, J.S. and T.J.C. Beebee. 1993. Reproductive strategies in a female-biased population of natterjack toads, Bufo calamita. Animal Behaviour 46: 1169-1175.

Dyson, M.L., N.I. Passmore, P.J. Bishop and S.P. Henzi. 1992. Male behavior and correlates of mating success in a natural population of African painted reed frogs (Hyperolius marmoratus). Herpetologica 48: 236-246.

Emlen, S.T. 1976. Lek organization and mating strategies in the bullfrog. Behavioral Ecology and Sociobiology 1: 283-313.

Emlen, S.T. and L.W. Oring. 1977. Ecology, sexual selection, and the evolution of mating systems. Science 197: 215-223.

Fellers, G.M. 1979. Mate selection in the gray treefrog, Hyla versicolor. Copeia 1979: 286-290. Fukuyama, K. and T. Kusano. 1989. Sexual size dimorphism in a Japanese stream-breeding frog, Buergeria buergeri (Rhacophoridae, Amphibia). In Current Herpetology in East Asia. M. Matsui, T. Hikida and R.C. Gorris (eds.). Herpetological Society of Japan, Kyoto.

Gatz, A.J., Jr. 1981. Non-random mating by size in American toads, Bufo americanus. Animal Behaviour 29: 1004-1012.

Gerhardt, H.C., R.E. Daniel, S.A. Perrill and S. Schramm. 1987. Mating behaviour and male mating success in the green treefrog. Animal Behaviour 35: 1490-1503.

Given, M.F. 1988a. Growth rate and the cost of calling activity in male carpenter frogs, Rana virgatipes. Behavioral Ecology and Sociobiology 22: 153-160. 
Given, M.F. 1988b. Territoriality and aggressive interactions of male carpenter frogs, Rana virgatipes. Copeia 1988: 411-421.

Godwin, G.J. and S.M. Roble. 1983. Mating success in male treefrogs, Hyla chrysoscelis (Anura: Hylidae). Herpetologica 39: 141-146.

Green, A.J. 1990. Determinants of chorus participation and the effects of size, weight and competition on advertisement calling in the tungara frog, Pbysalaemus pustulosus (Leptodactylidae). Animal Behaviour 39: 620-638.

Greer, B.J. and K.D. Wells. 1980. Territorial and reproductive behavior of the tropical American frog Centrolenella fleischmanni. Herpetologica 36: 318-326.

Halliday, T. and M. Tejedo. 1995. Intrasexual selection and alternative mating behaviour. Chapter 1 in Amphibian Biology. Volume 2, Social Behaviour. H. Heatwole and B.K. Sullivan (eds.). Surrey Beatty \& Sons PTY Limited, Chipping Norton, New South Wales. Howard, R.D. 1978. The evolution of mating strategies in bullfrogs, Rana catesbeiana. Evolution 32: $850-871$.

Jacobson, S.K. 1985. Reproductive behavior and male mating success in two species of glass frogs (Centrolenidae). Herpetologica 41: 396-404.

Jennions, M.D., P.R.Y. Backwell and N.I. Passmore. 1992. Breeding behaviour of the African frog, Chiromantis xerampelina: multiple spawning and polyandry. Animal Behaviour 44: 10911100.

Kagarise Sherman, C. 1980. A comparison of the natural history and mating systems of two anurans: Yosemite toads (Bufo canorus) and black toads (Bufo exsul). Ph.D. dissertation, University of Michigan, Ann Arbor, Michigan. 
Kluge, A.G. 1981. The life history, social organization, and parental behavior of Hyla rosenbergi Boulenger, a nest-building gladiator frog. Miscellaneous Publications Museum of Zoology, University of Michigan No. 160.

MacDonald, C. 1997. Reproductive success, mating strategies, and long-term population trends in the bullfrog, Rana catesbeiana (Anura: Ranidae). M.Sc. thesis, University of Guelph, Guelph, Ontario.

MacDonald, C. and R.J. Brooks. 1997. Abundance and age distribution of three species of ranid frogs in Algonquin park. Progress Report to the Ontario Ministry of Natural Resources, Department of Zoology, University of Guelph, Guelph, Ontario.

Magnhagen, C. 1991. Predation risk as a cost of reproduction. Trends in Ecology and Evolution 6: 183-186.

Martins, M. 1993. Observations on the reproductive behaviour of the smith frog, Hyla faber. Herpetological Journal 3: 31-34.

Morris, M.R. 1989. Female choice of large males in the treefrog Hyla chrysoscelis: the importance of identifying the scale of choice. Behavioral Ecology and Sociobiology 25: 275-281.

Murphy, C.G. 1992. The mating system of the barking treefrog (Hyla gratiosa). Ph.D. dissertation, Cornell University, Ithaca, New York.

Murphy, C.G. 1994a. Chorus tenure of male barking treefrogs, Hyla gratiosa. Animal Behaviour 48: 763-777.

Murphy, C.G. 1994b. Determinants of chorus tenure in barking treefrogs (Hyla gratiosa). Behavioral Ecology and Sociobiology 34: 285-294.

Murphy, C.G. 1999. Nightly timing of chorusing by male barking treefrogs (Hyla gratiosa): the influence of female arrival and energy. Copeia 1999: 333-347. 
Obbard, M.E. 1977. A radio-telemetry and tagging study of activity in the common snapping turtle, Chelydra serpentina. M.Sc. thesis, University of Guelph, Guelph, Ontario.

Perrill, S.A. 1984. Male mating behavior in Hyla regilla. Copeia 1984: 727-732.

Pianka, E.R. and W.S. Parker. 1975. Age-specific reproductive tactics. The American Naturalist 109: 453-464.

Pough, F.H., W.E. Magnusson, M.J. Ryan, K.D. Wells and T.L. Taigen. 1992. Behavioral energetics. Chapter 14 in Environmental Physiology of the Amphibians. M.E. Feder and W.W. Burggren (eds.). University of Chicago Press, Chicago, Illinois.

Ritke, M.E. and R.D. Semlitsch. 1991. Mating behavior and determinants of male mating success in the gray treefrog, Hyla chrysoscelis. Canadian Journal of Zoology 69: 246-250.

Robertson, J.G.M. 1986. Male territoriality, fighting and assessment of fighting ability in the Australian frog Uperoleia rugosa. Animal Behaviour 34: 763-772.

Roithmair, M.E. 1994. Male territoriality and female mate selection in the dart-poison frog Epipedobates trivittatus (Dendrobatidae, Anura). Copeia 1994: 107-115.

Ryan, M.J. 1983. Sexual selection and communication in a Neotropical frog, Physalaemus pustulosus. Evolution 37: 261-272.

Ryan, M.J. 1985. The Túngara Frog: A Study in Sexual Selection and Communication. University of Chicago Press, Chicago, Illinois.

Ryser, J. 1989. Weight loss, reproductive output, and the cost of reproduction in the common frog, Rana temporaria. Oecologia 78: 264-268.

Searcy, W.A. and M. Andersson. 1986. Sexual selection and the evolution of song. Annual Review of Ecology and Systematics 17: 507-533. 
Shirose, L.J. 1990. Population ecology of the postmetamorphic bullfrog (Rana catesbeiana Shaw) in Algonquin Provincial Park, Ontario. M.Sc. thesis, University of Guelph, Guelph, Ontario.

Shirose, L.J., R.J. Brooks, J.R. Barta and S.S. Desser. 1993. Intersexual differences in growth, mortality, and size at maturity in bullfrogs in central Ontario. Canadian Journal of Zoology 71: 2363-2369.

Stearns, S.C. 1992. The Evolution of Life Histories. Oxford University Press, New York, New York.

Sullivan, B.K. 1982a. Sexual selection in the great plains toad (Bufo cognatus). Behaviour 84: 258264.

Sullivan, B.K. 1982b. Sexual selection in Woodhouse's toad (Bufo woodhousez): I. chorus organization. Animal Behaviour 30: 680-686.

Sullivan, B.K. 1987. Sexual selection in Woodhouse's toad (Bufo woodhouse1): III. seasonal variation in male mating success. Animal Behaviour 35: 912-919.

Sullivan, B.K. 1989. Mating system variation in Woodhouse's toad (Bufo woodhousiz). Ethology 83: $60-68$.

Sullivan, B.K. and S.H. Hinshaw. 1992. Female choice and selection on male calling behaviour in the grey treefrog Hyla versicolor. Animal Behaviour 44: 733-744.

Tabachnick, B.G. and L.S. Fidell. 1996. Using Multivariate Statistics, Third Edition. HarperCollins College Publishers, New York, New York.

Tejedo, M. 1992. Large male mating advantage in natterjack toads, Bufo calamita: sexual selection or energetic constraints? Animal Behaviour 44: 557-569.

Telford, S.R. and J. Van Sickle. 1989. Sexual selection in an African toad (Bufo gutteralis): the roles of morphology, amplexus displacement and chorus participation. Behaviour 110: 62-75. 
Townsend, D.S. and M.M. Stewart. 1994. Reproductive ecology of the Puerto Rican frog Eleutherodactylus coqui. Journal of Herpetology 28: 34-40.

Wagner, W.E., Jr. and B.K. Sullivan. 1995. Sexual selection in the Gulf Coast toad, Bufo valliceps: female choice based on variable characters. Animal Behaviour 49: 305-319.

Wells, K.D. 1976. Territorial behavior of the green frog (Rana clamitans). Ph.D. dissertation, Cornell University, Ithaca, New York.

Wells, K.D. 1977. The social behaviour of anuran amphibians. Animal Behaviour 25: 666-693.

Wells, K.D. 1978. Territoriality in the green frog (Rana clamitans): vocalizations and agonistic behaviour. Animal Behaviour 26: 1051-1063.

Woodward, B. 1982. Male persistence and mating success in Woodhouse's toad (Bufo woodhouset). Ecology 63: 583-585.

Woolbright, L.L. and M.M. Stewart. 1987. Foraging success of the tropical frog, Eleutherodactylus coqui: the cost of calling. Copeia 1987: 69-75.

Zahavi, A. 1975. Mate selection: a selection for a handicap. Journal of Theoretical Biology 53: 205-214.

\section{APPENDIX 1: INTERANNUAL COMPARISONS OF CHORUSING SEASONS}

\section{INTRODUCTION}

Early in the spring of 1998, a section of the dam on Lake Sasajewun washed away. This caused the lake to drop approximately $1.4 \mathrm{~m}$ below normal midsummer leveis (Figure A1.1), and a reduction in lake surface area of approximately $50 \%$ (Figure A1.2). Due to this catastrophic perturbation in the habitat of the bullfrog population, any experimental results relying solely on one year of data are potentially non-generalizable. To determine if bullfrog behaviour and the 


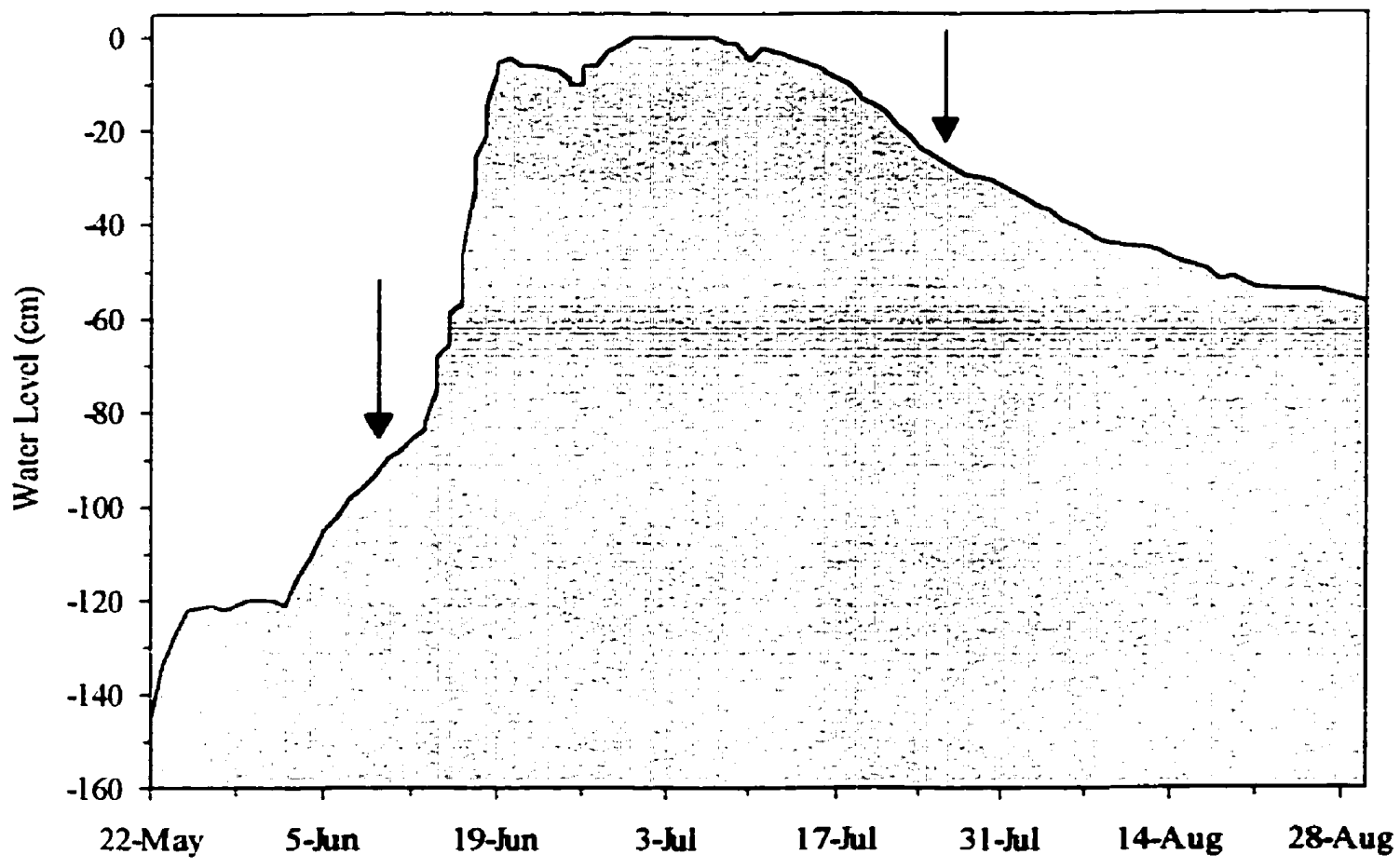

Figure A1.1. Relative change in water level of Lake Sasajewun during the summer of 1998. The zero level represents the maximum level reached during the summer of 1998 and is probably similar to normal midsummer water levels. Arrows indicate the beginning and end of bullfrog chorusing season. 


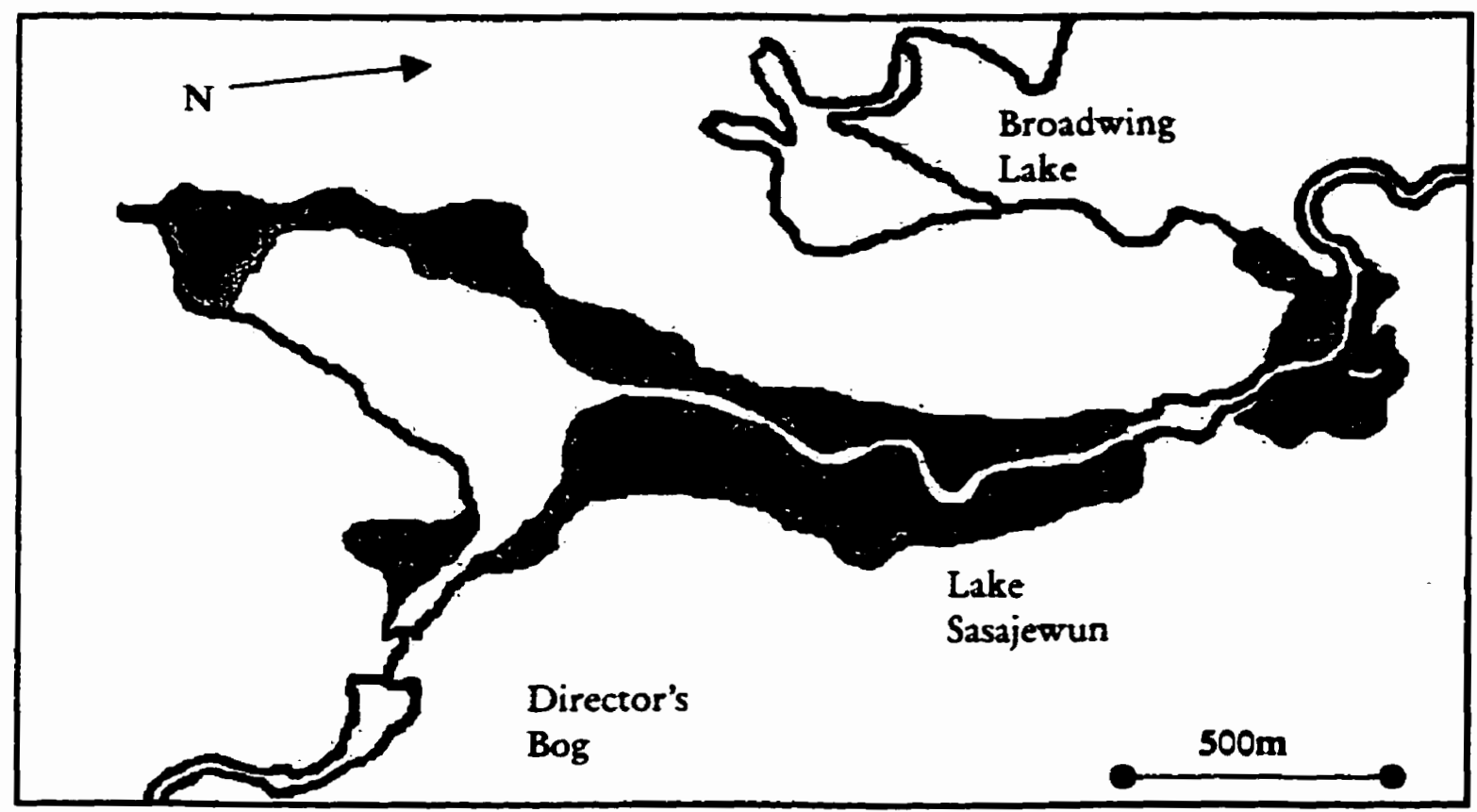

Figure A1.2. Lake Sasajewun, Algonquin Provincial Park, Ontario. Light grey areas represent lake bottom that was exposed to the air until approximately 22 May 1998. These areas are covered by floating aquatic vegetation when submerged and are also the areas within which all bullfrog chorusing activity takes place. Black ellipses are bullfrog chorusing sites. 
characteristics of the bullfrog chorusing season in 1998 were anomalous or within the range of "normal" yearly variation, male bullfrogs caught in 1998 were compared with previous years in which the bullfrog choruses on Lake Sasajewun were monitored. Chorusing males were sampled infrequently during the summers of 1994 and 1995; therefore, only the physical characteristics of male bullfrogs may be used to compare with subsequent years. However, choruses were censused intensively during the summers of 1996, 1997 and 1998, with only eight, two and zero nights missed respectively due to inclement weather. Male bullfrog chorus behaviour variables such as chorus tenure can be compared among these three years.

\section{METHODS}

Data from 1998 were compared to previous years with respect to a variety of variables, which can be grouped into two categories, 1) characteristics of individual male bullfrogs and 2) characteristics of the chorusing season. Male bullfrogs from 1998 were compared to males from 1994, 1995, 1996 and 1997 on the basis of body size (snout-urostyle length), initial condition, final condition, condition change and residual condition change. Chorus censusing was done less intensively in 1994 and 1995 than in subsequent years, therefore, the final chorusing dates of most frogs are probably underestimates of the true final dates of these frogs. Consequently, final condition in these two years was likely overestimated. However, this may not affect the ability to compare final condition among years because bullfrogs still lost condition in the time span over which their condition was measured. In 1996 and 1997, bullfrogs were not weighed on each night of chorus censusing; instead a sequence of nights was chosen near the end of the chorusing season and all frogs present on those nights were weighed. Therefore, final condition was not measured from all bullfrogs, and for those that were, their final condition may have been measured well 
before they actually ended their chorus tenure. In these analyses, only frogs for which final condition covers at least $60 \%$ of the span of their chorus tenures were used.

Bullfrogs from 1998, 1997 and 1996 were compared with respect to chorus tenure, dominant tenure, chorus tenure span, chorus tenure corrected for span (a measure of attendance consistency), dominant tenure corrected for chorus tenure (a measure of chorusing effort), the number of different choruses visited and the number of chorus changes. The effects of different handling procedures were compared between 1996, 1997 and 1998 by examining the number of days needed for males to resume chorusing after their initial capture and handling, and whether males returned on their second night to the same chorus in which they were initially captured. If there were differences in these variables, then it was predicted that disturbed frogs would be more likely to resume chorusing after a longer period of time and return to a different chorus following initial capture. The 1996, 1997 and 1998 chorusing seasons were compared on nightly average chorus size, nightly population of males, nightly population of dominant males, season duration, cumulative number of males and male survivorship.

All statistical analyses were carried out using Statistical Package for the Social Sciences (SPSS) Version 8.0. All tests were conducted at the $\alpha=0.05$ level and were two-tailed unless otherwise noted. Multiple comparisons were made using Fisher's LSD test. 


\section{RESULTS}

There were differences among years for snout-urostyle length $\left(\mathrm{F}_{4,202}=7.033, \mathrm{p}<0.001\right)$, initial condition $\left(F_{4,202}=8.227, p<0.001\right)$, final condition $\left(F_{4,202}=7.564, p<0.001\right)$, condition change $\left(F_{4,202}=8.247, p<0.001\right)$ and residual condition change $\left(F_{4,202}=10.905, p<0.001\right)$. Chorusing male bullfrogs from 1998 differed from: a) 1994 and 1996 for snout-urostyle length ( $p<0.018$, Figure A1.3), b) 1994, 1995, 1996 and 1997 for initial condition $(p<0.004$, Figure A1.4), c) 1994 and 1997 for final condition ( $p<0.013$, Figure A1.5), d) 1996 and 1997 for condition change ( $p<0.014$, Figure A1.6) and e) 1996 and 1997 for residual condition change $(\mathrm{p}<0.005$, Figure A1.7)

One-way ANOVA revealed differences in chorus tenure among years $\left(F_{2,315}=3.280\right.$, p $<0.040$ ) and subsequent post-hoc tests showed that 1998 male bullfrogs had longer chorus tenures than 1996 males (mean difference $=3.69 \pm 1.512(\mathrm{SE})$ nights, $\mathrm{p}<0.015$ ). There were also differences among years in the number of choruses visited $\left(F_{2,315}=11.215, p<0.001\right)$ and the number of chorus changes $\left(F_{2,315}=8.004, p<0.001\right)$. Bullfrogs from 1998 visited more choruses during their chorus tenure than both 1996 bullfrogs (mean difference $=0.87 \pm 0.185$ (s.d.) chorus locations, $\mathrm{p}<0.001$ ) and 1997 bullfrogs (mean difference $=0.57 \pm 0.183($ s.d.) chorus locations, $p<0.010$ ). Bullfrogs from 1998 changed chorus locations more often than 1996 bullfrogs (mean difference $=1.07 \pm 0.270$ (s.d.) chorus changes, $p<0.001$ ). However, there were no differences in males' dominant tenure $\left(F_{2,315}=1.837, p<0.162\right)$, tenure span $\left(F_{2,315}=0.100, p<0.905\right)$, chorus tenure corrected for tenure span (ANCOVA: $F_{2,314}=3.034, p<0.051$ ) or dominant tenure corrected for chorus tenure (ANCOVA: $F_{2.31+}=1.604, p<0.204$ ). 


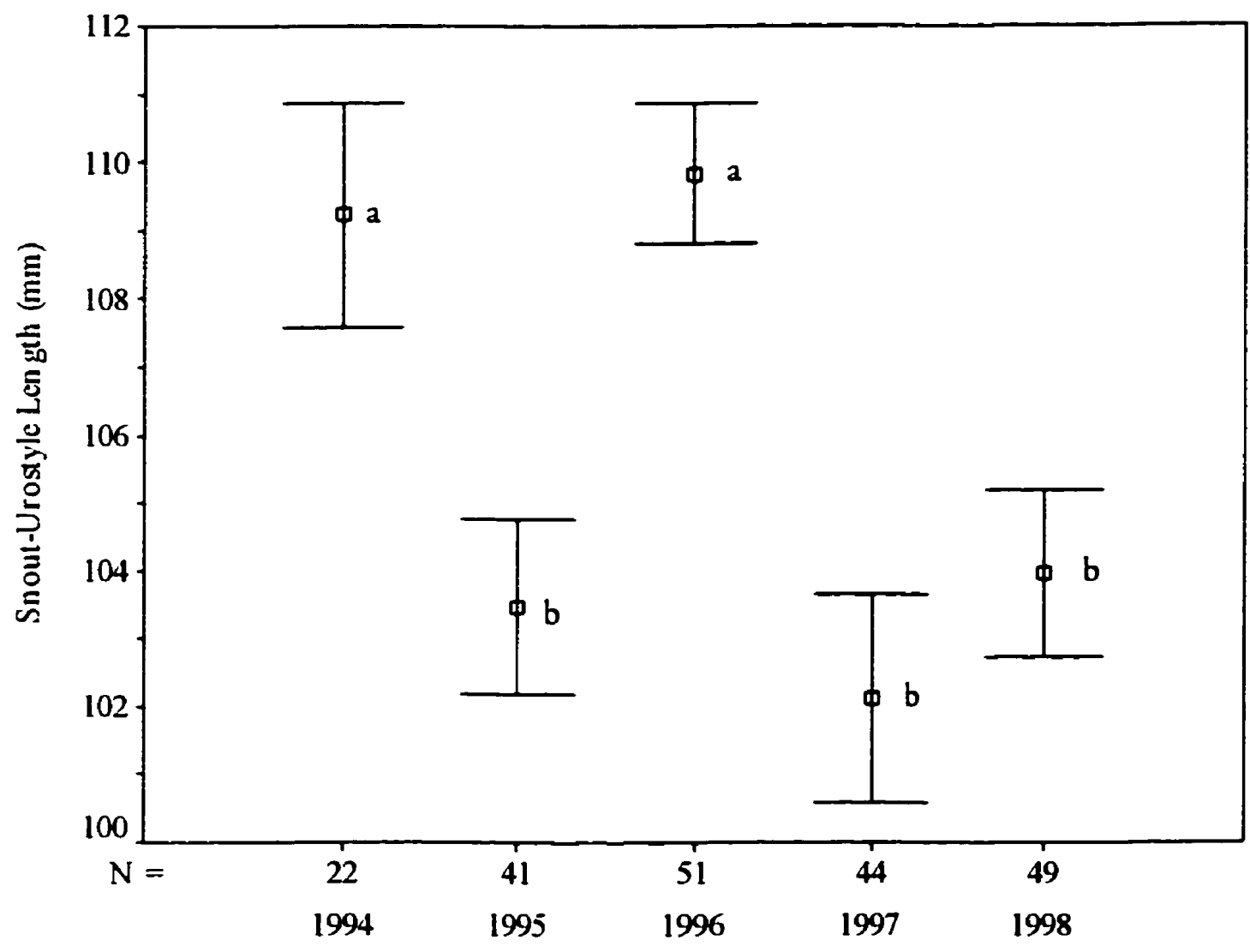

Figure A1.3. Plot of mean initial size (snout-urostyle length) of male bulltrogs participating in chorus activity from 1994 to 1998 . Sample sizes are indicated along the $x$-axis, bars represent one standard error above and below the mean. Means that share the same letter are not significantly different. 


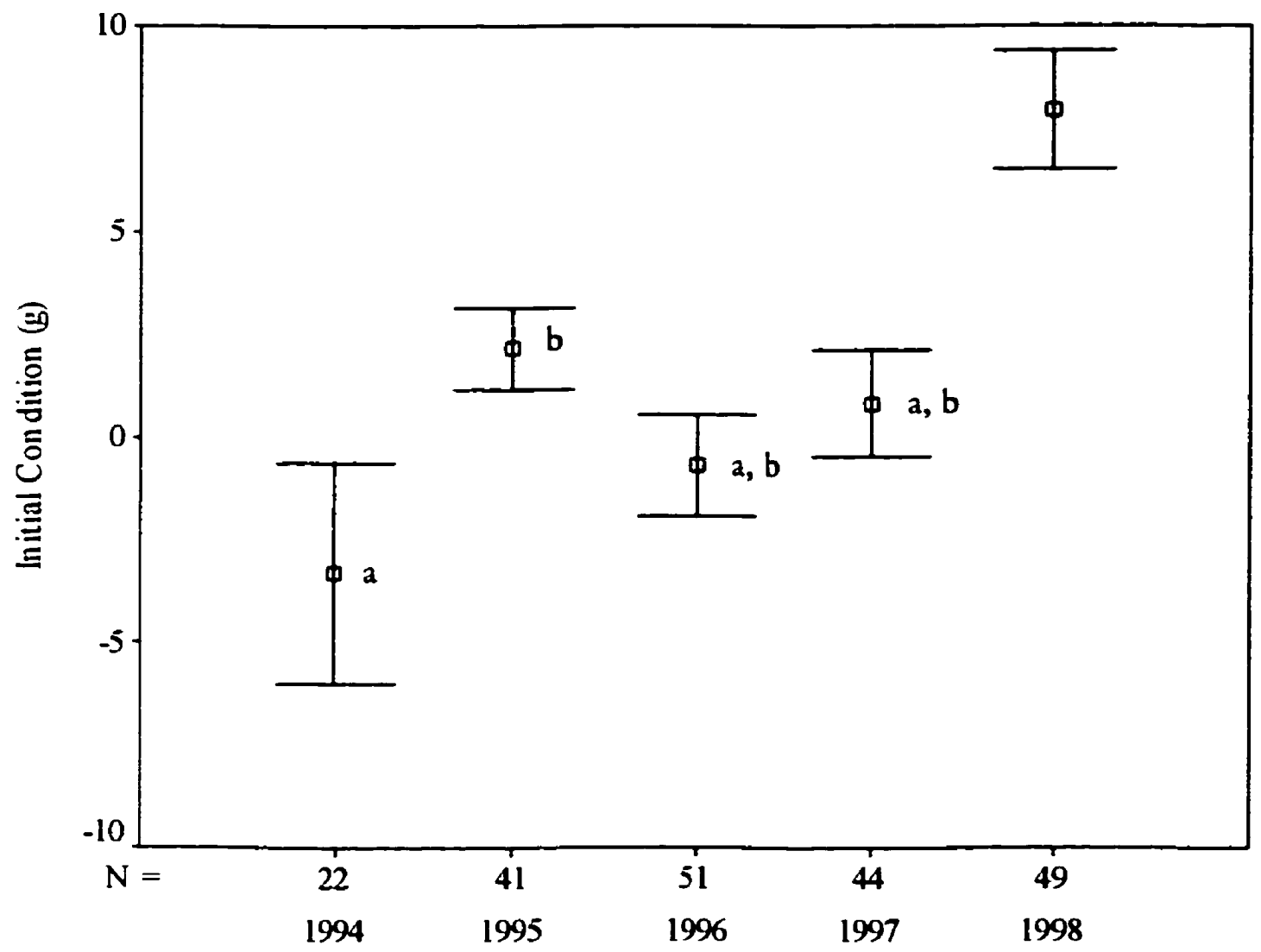

Figure A1.4. Plot of mean initial condition of male bullfrogs participating in chorus activity from 1994 to 1998. Sample sizes are indicated along the $\mathbf{x}$-axis, bars represent one standard error above and below the mean. Means that share the same letter are not significantly different. 


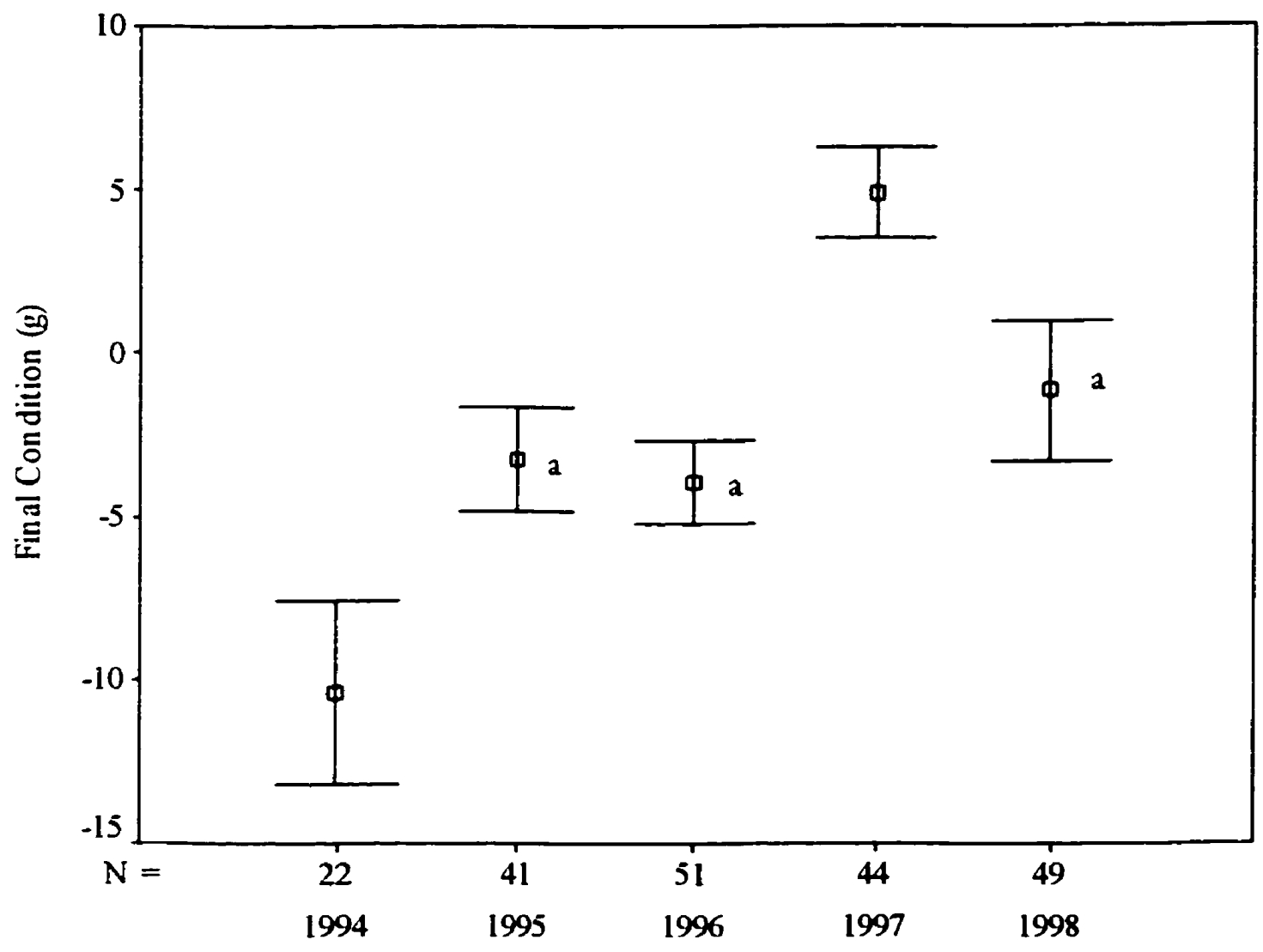

Figure A1.5. Plot of mean final condition of male bullfrogs participating in chorus activity from 1994 to 1998 . Sample sizes are indicated along the $x$-axis, bars represent one standard error above and below the mean. Means that share the same letter are not significantly different. 


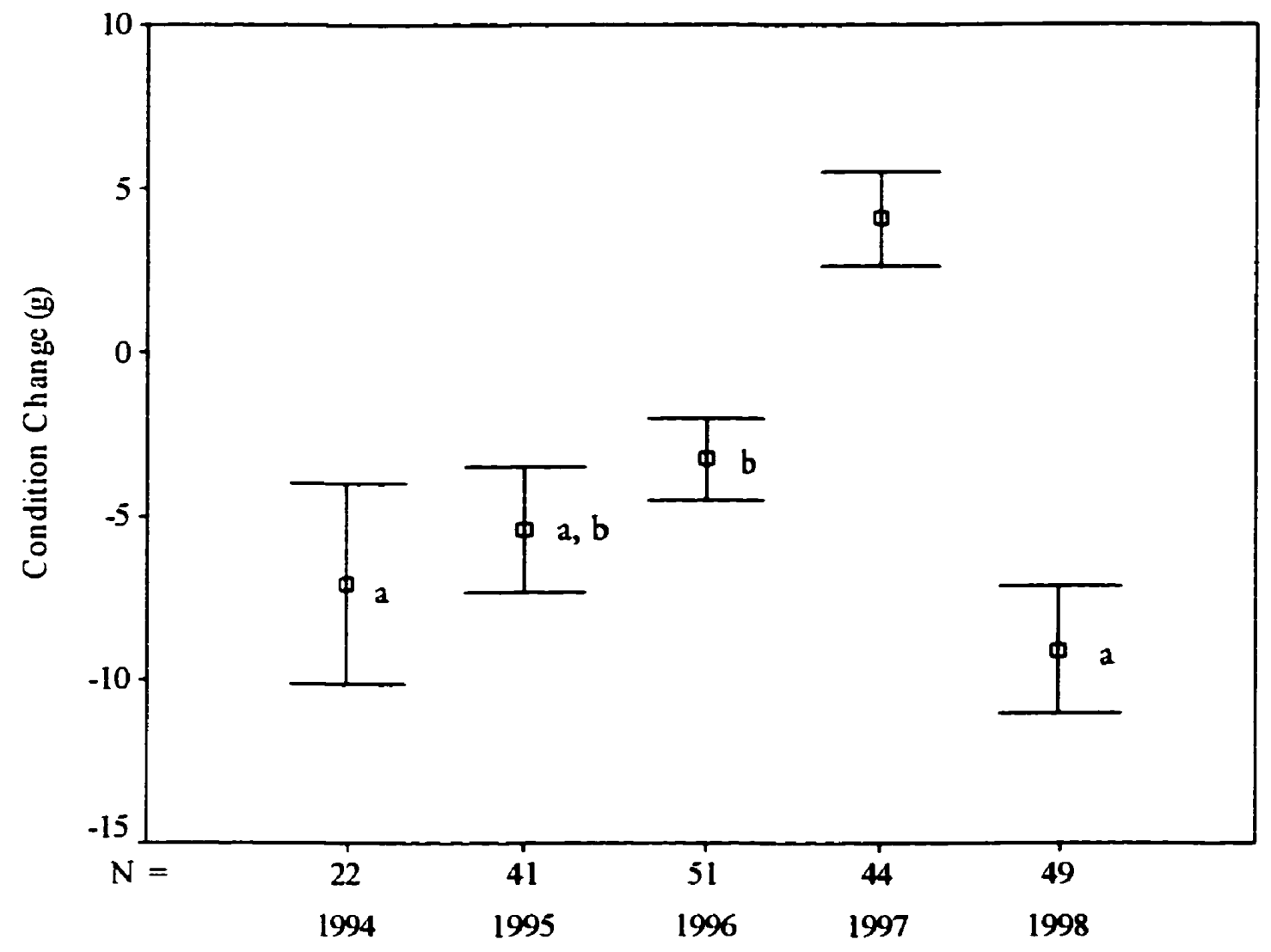

Figure A1.6. Plot of mean condition change of male bullfrogs participating in chorus activity from 1994 to 1998 . Sample sizes are indicated along the $x$-axis, bars represent one standard error above and below the mean. Means that share the same letter are not significantly different. 


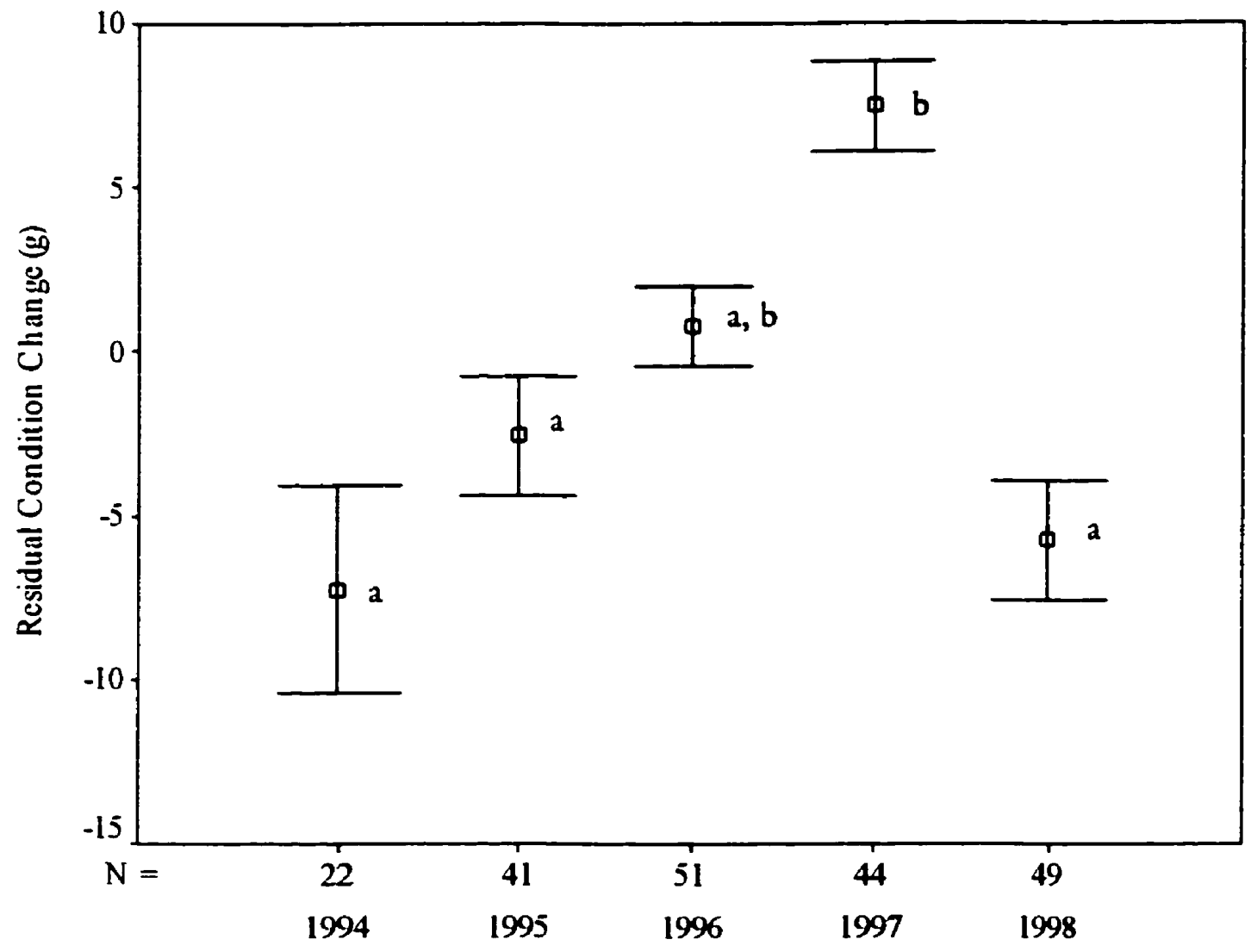

Figure A1.7. Plot of mean residual condition change of male bullfrogs participating in chorus activity from 1994 to 1998 . Sample sizes are indicated along the $\mathbf{x}$-axis, bars represent one standard error above and below the mean. Means that share the same letter are not significantly different. 
There were differences among years in whether males returned to the same chorus $\left(\chi^{2}+=12.119, p<0.005\right)$. Bullfrogs from 1998 returned to the same chorus less often than in the previous two chorusing seasons (1996 and 1997 pooled) $\left(\chi^{2}=12.110, p<0.001\right)$. However, there were no differences among years in the number of days males took to resume chorusing following their night of first capture (Kruskal-Wallis: $\chi^{2} 2=3.470, \mathrm{p}<0.177$ ).

There were no differences among years in the nightly average chorus sizes $\left(F_{2.129}=2.918\right.$, $p<0.059)$ or average nightly number of calling males $\left(F_{2,120}=2.982, p<0.055\right)$. However, there was a difference among years in the average nightly number of males present $\left(F_{2,130}=3.982\right.$, $\mathrm{p}<0.022) ; 1997$ had a higher nightly average than 1998 (mean difference $=8.86 \pm 3.296($ s.d.) males, $p<0.031$ ). Survivorship, the proportion of chorusing population made up of experienced males from the previous chorusing season, did not differ among the years 1995 to $1998 \alpha^{2}{ }^{2}=3.13$, $\mathrm{p}<0.5)$

\section{Discussion}

Male bullfrogs participating in the 1998 chorusing season were physically different from males from previous chorusing seasons. They differed from: a) 1994 and 1996 in snout-urostyle length, b) 1994, 1995, 1996 and 1997 in initial condition, c) 1994 and 1997 in final condition, d) 1996 and 1997 in condition change and e) 1996 and 1997 in residual condition change.

Although 1998 males seemed to begin their chorus tenure in significantly better condition than frogs from previous years, there does not seem to be any pattern consistent with the idea that 1998 was an anomalous year in terms of the physical characteristics of the male bullfrogs.

The chorusing behaviour of males from 1998 also did not significantly differ from males of the 1996 and 1997 chorusing seasons. Dominant tenure, span of chorus tenure, dominant tenure 
corrected for chorus tenure and chorus tenure corrected for tenure span were all not significantly different among years. There was a significant difference in the chorus tenures of 1998 and 1996 bullfrogs, with 1998 males participating for a greater number of nights. However, this is likely an experimental artifact and not a real biological difference. In the summer of 1996, there was a total of eight nights where choruses on Lake Sasajewun were not censused due to inclement weather. Thus, the mean chorus tenure of 1996 chorusers may be an underestimate of the true value. Males in 1998 did not differ from previous years in the number of days they took to resume chorusing. However, they returned to the same chorus on their second night of chorusing less frequently than males from 1996 and 1997, visited more choruses than males from 1996 and 1997, and changed choruses more frequently than males from 1996. These results are not surprising when one considers that the surface area of Lake Sasajewun (and consequently the number of available chorusing sites) changed dramatically over the first two weeks of the 1998 chorusing season (Figure A1.1). As the season progressed, lake water level rose, lake surface area increased and more chorusing sites became available. One might expect that, as more options became available, male bullfrogs in the 1998 chorusing season would be more likely to choose different choruses.

Snapping turtles were observed in choruses more often in 1998 than in previous years (pers. obs.); probably because lake water depth was lower in 1998 than in previous years, allowing researchers to clearly view the bottom of the lake. As a result of this low water level, chorusing bullfrogs may have been more visible to foraging snapping turtles. The drastic drop in lake level may have had an indirect effect on within-chorus mortality, and by chance have had a differential effect on third year chorusers. Two out of three third year chorusers were probably the victims of snapping turtle attacks (one had an obvious, but non-fatal bite wound and the other's final absence correlated with a night of increased snapping turtle activity). In 1996 and 1997, third year 
chorusers survived well into the latter stages of the chorusing season (final dates: 1996 = 36 and 46 [out of 46 nights of chorusing]; $1997=40,41$ and 44 [out of 49 nights of chorusing]) whereas in 1998, third year chorusers did not (final dates: $1998=7,20$ and 46 [out of 46 nights of chorusing]. Therefore the mean chorus tenure of third year chorusers from 1998 was shorter and much more variable than that of third year chorusers from 1996 or 1997.

The greatest effect of the 1998 spring Lake Sasajewun dam break seems to have been on the lake's water level and on the cumulative number of male bullfrogs that participated in chorusing activity. Physically and behaviourally, chorusing male bullfrogs from 1998 were different from bullfrogs from previous years, but, there was no consistent pattern to these differences. However, within-chorus mortality may have increased in 1998 due to the shallower water depth. The year 1998 was not anomalous in terms of bullfrog chorusing behaviour, and therefore the results of the preceding study into the determinants of chorus tenure in male bullfrogs are generalizable.

\section{APPENDIX 2: ALTERNATTVE EXPLANATIONS OF ABBREVIATED TENURE}

\section{INIRODUCTION}

Annual mortality of adult male bullfrogs is very high in Lake Sasajewun with third year chorusers never surviving for another season (Table A2.1). This is probably because there is an exceptionally long over-wintering period at this northern limit of the species' distribution (Conant and Collins 1998). Males with low residual reproductive value are more likely to trade future survival and reproduction for current reproduction than males with high residual reproductive value (Pianka and Parker 1975). Because of the increase in mortality after two

seasons of tenure (Table A2.1), third year chorusing males may be more likely to trade potential 
future reproductive success for current reproductive success than younger males (first year chorusers or second year chorusers). If this is the case, then third year chorusers should have longer chorus tenures and dominant tenures than second year chorusers and first year chorusers.

Because there is no reliable method of age-determination for anurans aside from marking newly transformed individuals and recapturing them at later dates, body size was used as an indicator of age (Halliday and Verrell 1988). Therefore, if age is positively related to chorus tenure and dominant tenure then body size should also be correlated with tenure.

Murphy (1994) proposed two other hypotheses to explain variation in chorus tenure: 1) males may be absent from choruses due to mortality from disease or predation and 2) males may be absent because they have switched chorusing sites and their absence is really sampling error. Although I did not design my study to test these two hypotheses (mortality and movement hypotheses respectively) explicitly, data were collected to qualitatively assess their importance in determining bullfrog chorus tenure.

\section{METHODS}

Age

Chorus tenure and dominant tenure were compared among the three experience classes (first year chorusers, second year chorusers and third year chorusers). Also, male body size (snout-urostyle length) was entered as the independent variable into bivariate regressions with both chorus tenure and dominant tenure. 
Table A2.1. Adult male bullfrog mortality from all years of chorus tenure study (MacDonald unpublished data). The proportions of each experience class surviving to the following year were tested using chi-square tests, however, there were no significant differences.

\begin{tabular}{llcccc}
\hline Year & Group & N Surviving & N Not Surviving & Total & Mortality (\%) \\
\hline 1994 & Total & 9 & 47 & 56 & 83.9 \\
& & & & & \\
1995 & Rookies & 15 & 73 & 88 & 83.0 \\
1995 & Veterans & 2 & 7 & 9 & 77.8 \\
1995 & Total & 17 & 80 & 97 & 82.5 \\
& & & & & \\
1996 & Rookies & 14 & 83 & 97 & 85.6 \\
1996 & $2^{\text {nd }}$ Year Veterans & 3 & 12 & 15 & 80.0 \\
1996 & $3^{\text {rd }}$ Year Veterans & 0 & 2 & 2 & 100 \\
1996 & Total & 17 & 97 & 114 & 85.1 \\
& & & & & \\
1997 & Rookies & 15 & 93 & 108 & 86.1 \\
1997 & $2^{\text {nd }}$ Year Veterans & 3 & 11 & 14 & 78.6 \\
1997 & $3^{\text {rd }}$ Year Veterans & 0 & 3 & 3 & 100 \\
1997 & Total & 18 & 104 & 122 & 85.2 \\
\hline
\end{tabular}




\section{Mortality Hypothesis}

To examine the hypothesis that bullfrog chorus tenure and dominant tenure is limited by mortality within the chorusing season, all observations of bullfrog predators (e.g. snapping turtles, Chelydra serpentina, river otters, Lutra canadensis, raccoons, Procyon lotor and great blue herons, Ardea herodias) within choruses during chorusing activity were noted and compared with the final dates of chorus tenure of male bullfrogs (i.e. the last night a male bullfrog was observed chorusing). All wounds present on males were noted.

\section{Movement Hypothesis}

The bodies of water surrounding Lake Sasajewun (Broadwing Lake, Kathlyn Lake, Lost Ray Lake, Mew Lake and Director's Bog) were censused a total of 17 times during the 1998 chorusing season to investigate whether variation in male chorus tenure was explained by movement between chorusing sites on different lakes (see Figure 1 above). Census protocols were the same as at Lake Sasajewun, except that bullfrogs were not weighed in the field. New males from other lakes were processed in the same way as males from Lake Sasajewun, except that: they were processed in the afternoon following initial capture instead of that night and they were not included in the feeding experiment. Frogs were returned to their chorus sites at the same time as individuals from the fed and sham-fed groups (see Methods, Tests of the Energetic Constraint Hypothesis above). 


\section{Analysis}

All statistical analyses were carried out using Statistical Package for the Social Sciences Version 8.0. All tests were conducted at the $\alpha=0.05$ level and were two-tailed unless otherwise noted.

\section{Results}

Age

Neither chorus tenure or dominant tenure were significantly different among first year chorusers, second year chorusers or third year chorusers (Figure A2.1). Body size was not significantly related to chorus tenure $\left(F_{1, n}=0.028, p<0.869\right.$, Figure A2.2a) or dominant tenure $\left(F_{1, \pi}=0.184, p<0.670\right.$, Figure $\left.A 2.2 b\right)$

\section{Mortality Hypothesis}

Twenty-nine of 82 male bullfrogs that participated in chorus activity on Lake Sasajewun during the 1998 chorusing season were captured after their final night of chorus tenure. Of these 29 , seventeen were captured after the chorus season during late summer in 1998 and an additional twelve returned to chorus on Lake Sasajewun in 1999 (four of the seventeen also returned).

Two males were observed with wounds on their bellies. One male was almost completely eviscerated and was never seen again, the other returned for five more nights in the next twelve before ending his tenure. By the end of his chorus tenure, this bullfrog's belly wound had partially healed. Two additional bullfrogs were observed with sores on ventral parts of their bodies (thigh and belly) that looked similar to, but less severe than the above 

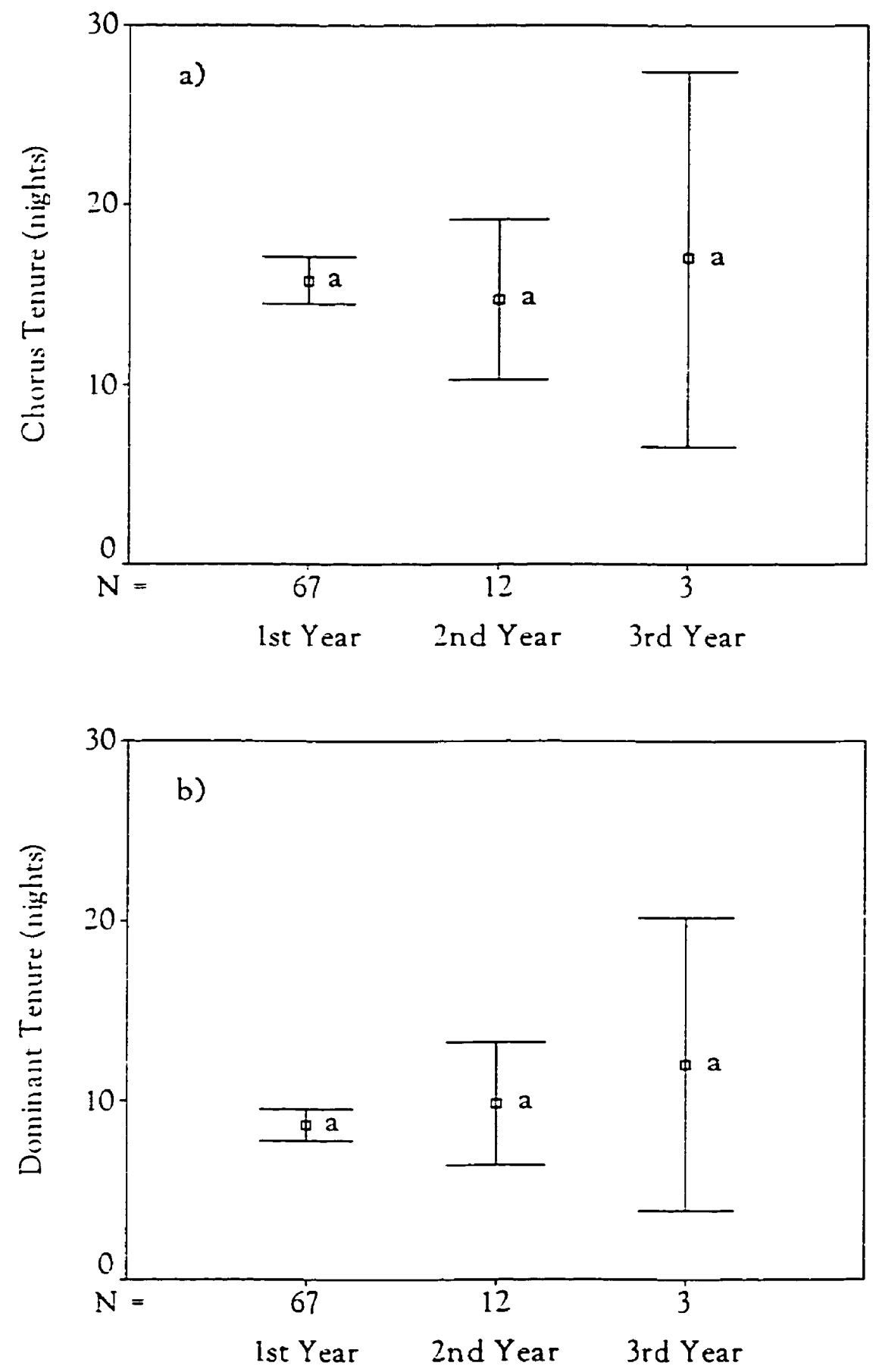

Figure A2.1. Plot of mean: a) chorus tenure and b) dominant tenure of the three experience classes (first vear chorusers, second year chorusers and third year chorusers) for the 1998 chorusing season. Sample sizes are ind icated along the $x$-axis, bars represent one standard error above and below the mean and means that share the same letter are not significantly different. 

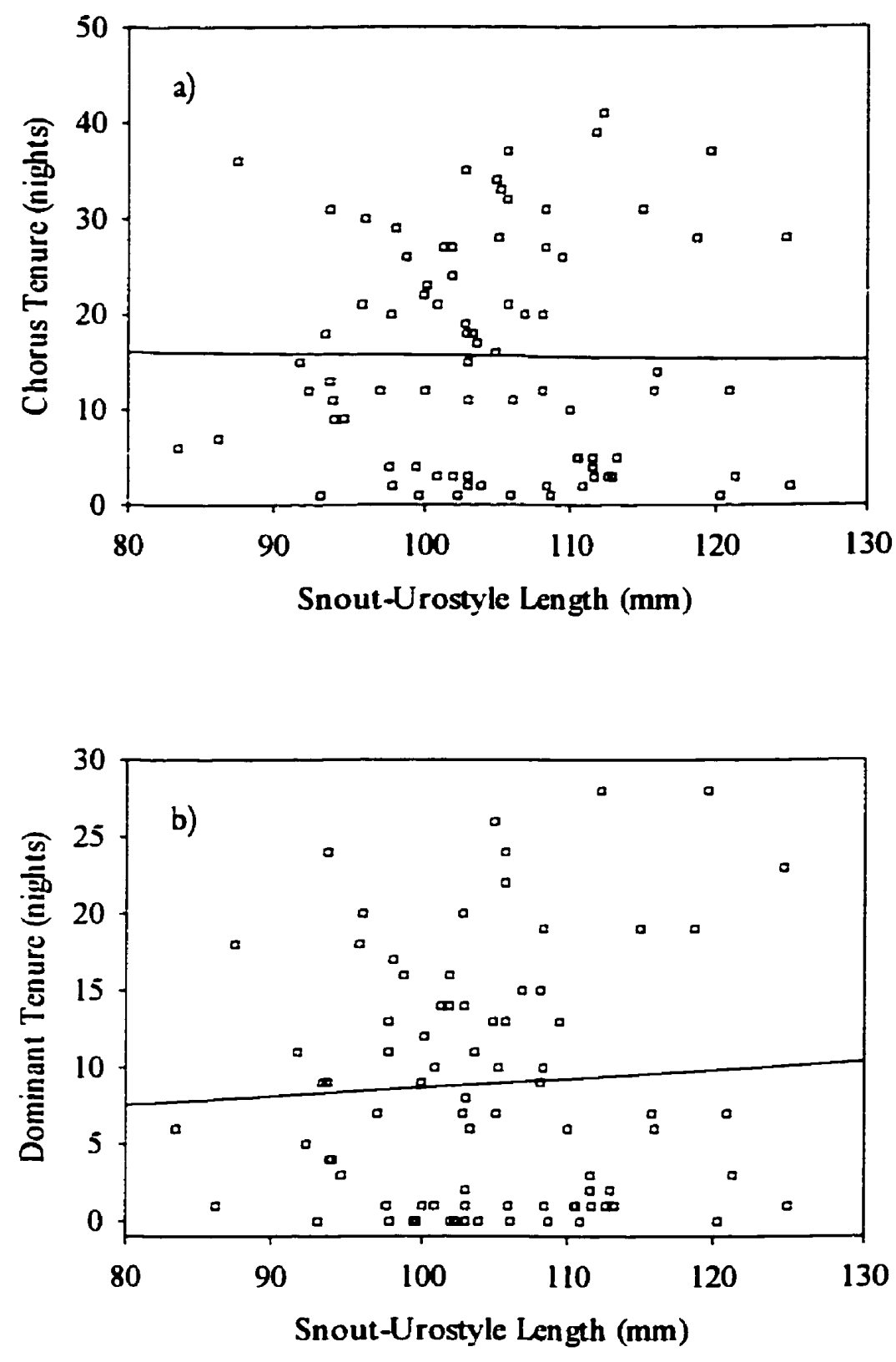

Figure A2.2. Relationship between body size (snout-urostyle length) and: a) chorus tenure and b) dominant tenure for the 1998 chorusing season. Body size was not significantly positively related to either chorus tenure $(r=-0.019, p<0.435, N=79)$ or dominant tenure $(r=0.049, p<0.336, N=79)$. 
wounds. From the position (ventral) and type (puncture) of all 4 putative wounds, the likely perpetrator was the common snapping turtle, which is present in Lake Sasajewun.

Snapping turtles were observed in choruses during chorusing activity on five nights $(17,18,19,21$ and 27 June 1998). Ten bullfrogs ended their chorus tenures either on, or had been seen until, these nights. On one night (17 June 1998), three snapping turtles were observed within bullfrog choruses; this corresponded with the last night of observed chorus tenure of eight male bullfrogs (Figure A2.3).

\section{Movement Hypothesis}

Three male bullfrogs out of 82 were observed participating in chorus activity on Lake Sasajewun after being captured initially on Broadwing Lake. No bullfrogs moved away from Lake Sasajewun to attend chorus activity at another lake. 


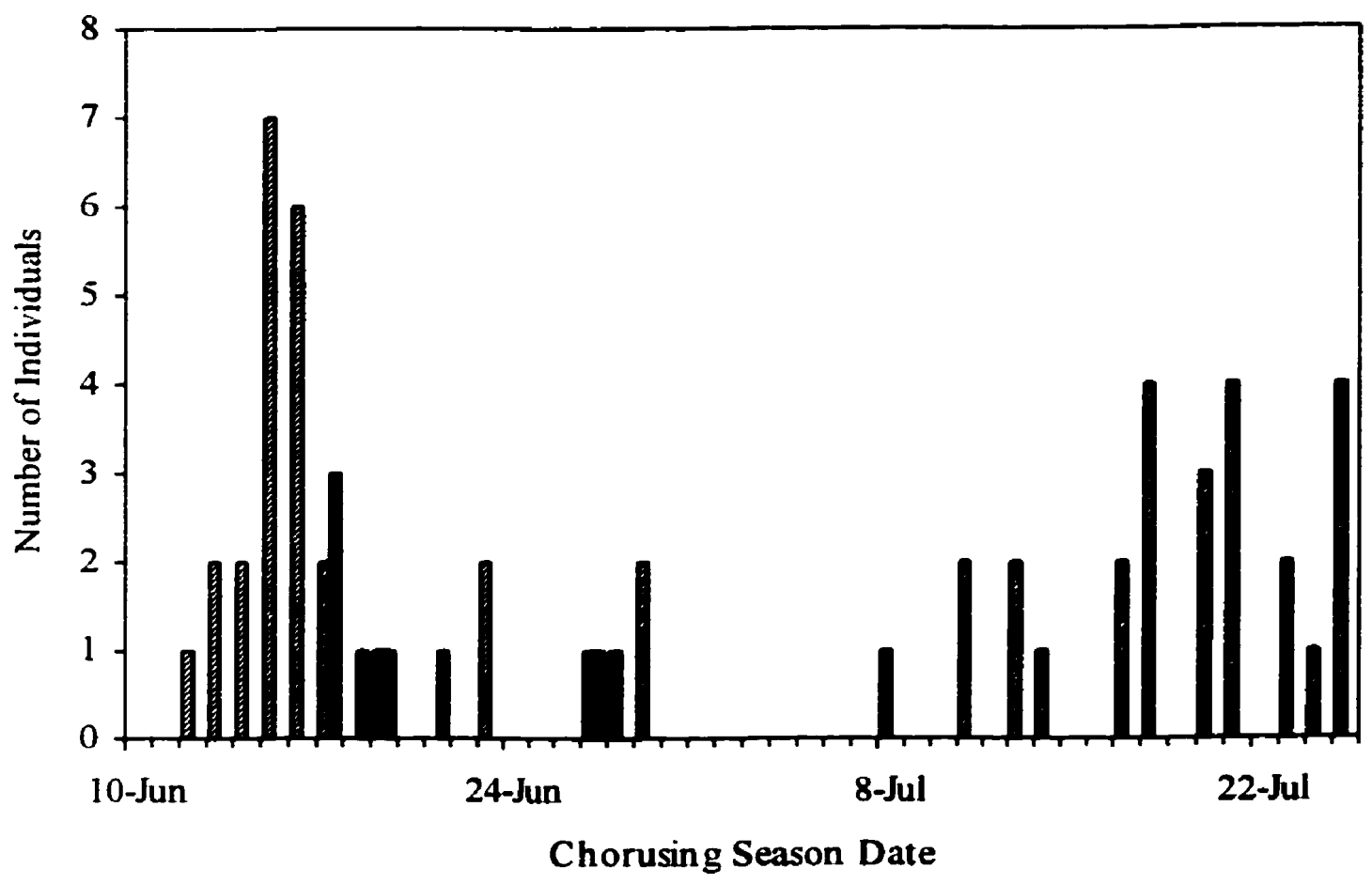

Figure A2.3. Distribution of final nights of chorus tenure of male bullfrogs (cross-hatched columns) and observations of snapping turtles (black columns) for the 1998 chorusing season. Only bullfrogs that were not seen after the chorusing season or the following summer ( $N$ = 53) are included on this figure. 


\section{Discussion}

Age

There were no significant relationships between age (approximated by either experience class or body size) and either chorus tenure or dominant tenure. These results are contrary to previous work done on Lake Sasajewun when age was found to be a significant determinant of chorus tenure (MacDonald 1997). This may be due to higher than usual mortality within the 1998 chorusing season caused by the drastic drop in lake level affecting experienced chorusers more than first year chorusers (see Appendix 1).

\section{Mortality Hypothesis}

Quantifying within-chorus mortality is problematic because bullfrogs do not leave the chorusing habitat during the chorusing season and males that are killed simply disappear. An upper limit on the importance of mortality in accounting for truncated chorus tenures (relative to the breeding season) of male bullfrogs can be established by calculating the percentage of the population of chorusing males that were not observed after their final night of chorus tenure. Therefore, mortality can at best account for 53 out of 82 terminal absences (64.6\%). Murphy (1993) was able to quantify within-chorus mortality in barking treefrogs because males travel to their chorus site from the surrounding forest and back again once nightly chorusing activity has ceased. A drift fence was placed around the study pond and males were captured as they moved into and out of the chorus. Approximately $20 \%$ of the population of chorusing males: did not leave the pond, were not found in amplexus and were never resighted, and therefore were assumed to have died within the chorus (Murphy 1994). In my study, direct measurement of within-chorus mortality was restricted to rare 
observations of fatally wounded bullfrogs. Only one bullfrog was known to have ended his chorus tenure because of a fatal wound from a snapping turtle.

An indirect measurement of within-chorus mortality was made by observations of predator activity within active choruses. Snapping turtles were observed during chorus activity on five nights, which corresponded to the terminal absences of ten bullfrogs. On one of these five nights, three snapping turtles were observed within active choruses and eight bullfrogs were never seen again. However, when compared with nights when no snapping turtles were observed, these nights do not seem unusual in terms of numbers of bullfrogs disappearing (Figure A2.3). Ryan et al. (1981) found a significant negative correlation between chorus size and predation risk to individual Physalaemus pustulosus. However, a quantitative assessment of the relationship between bullfrog chorus size and the risk of predation is not possible because observations of both bullfrog mortality and the presence of predators are too few.

\section{Movement Hypothesis}

It does not appear that movement between chorusing locations (i.e. between lakes) had any effect on estimation of bullfrog chorus tenure. In seventeen censuses of four nearby lakes and bogs (Broadwing Lake: ten censuses, Lost Ray Lake: one census, Kathlyn Lake: two censuses, Mew Lake: three censuses and Director's bog: one census) no bullfrogs were captured that had previously been captured on Lake Sasajewun during the 1998 chorusing season. However, three out of the 53 males that were captured at these alternate chorusing locations migrated to Lake Sasajewun during the 1998 chorusing season and participated in chorusing activity. 
Previous work has revealed variation between species in the amount of movement of male anurans among chorusing sites. Although male túngara frogs (Physalaemus pustulosus) attended chorus activity inconsistently, they did not visit other chorusing locations during absences from their main chorusing site (Green 1990). Murphy (1994) found that a large proportion (1988: 148 of $162=91.3 \%, 1990: 548$ of $634=86.4 \%$ ) of male barking treefrogs could have chorused at secondary locations before censusing was started at his main study site. Of these individuals, only a small proportion was found participating in chorusing activity at a secondary location (1988: 24 of $148=16.2 \%, 1990: 32$ of $548=5.8 \%$; Murphy 1994). In contrast, about half of the population of chorusing male natterjack toads at Woolmer Forest switched between several chorusing sites in each of three study seasons (Denton and Beebee 1993).

\section{LTTERATURE CITED}

Conant, R. and J.T. Collins. 1998. A field guide to reptiles and amphibians: eastern and central North America. Houghton Mifflin, Boston, Massachusetts.

Denton, J.S. and T.J.C. Beebee. 1993. Reproductive strategies in a female-biased population of natterjack toads, Bufo calamita. Animal Behaviour 46: 1169-1175.

Green, A.J. 1990. Determinants of chorus participation and the effects of size, weight and competition on advertisement calling in the tungara frog, Pbysalaemus pustulosus (Leptodactylidae). Animal Behaviour 39: 620-638.

Halliday, T.R. and P.A. Verrell. 1988. Body size and age in amphibians and reptiles. Journal of Herpetology 22: 253-265. 
MacDonald, C. 1997. Reproductive success, mating strategies, and long-term population trends in the bullfrog, Rana catesbeiana (Anura: Ranidae). M.Sc. thesis. University of Guelph, Guelph, Ontario.

Murphy, C.G. 1993. A modified drift fence for capturing treefrogs. Herpetological Review 24: $143-145$.

Murphy, C.G. 1994. Determinants of chorus tenure in barking treefrogs (Hyla gratiosa). Behavioral Ecology and Sociobiology 34: 285-294.

Pianka, E.R. and W.S. Parker. 1975. Age-specific reproductive tactics. The American Naturalist 109: 453-464.

Ryan, M.J., M.D. Tuttle and L.K. Taft. 1981. The costs and benefits of frog chorusing behavior. Behavioral Ecology and Sociobiology 8: 273-278.

\section{APPENDIX 3: RESIDUAL CONDITION CHANGE}

In his study of the determinants of chorus tenure in the barking treefrog, Hyla gratiosa, Chris Murphy used multiple regression to examine the influence of male body condition on chorus tenure. He calculated three condition variables for a sample of males, they were: initial condition, final condition, and rate of change in condition. Initial condition and final condition were calculated as described in Methods, Tests of the Energetic Constraint Hypothesis, above. Rate of change in condition was calculated as follows,

$v=\Delta / t$ (equation A3.1)

where, $v=$ rate of change in condition

$\Delta=$ change in condition (i.e. cond.rinal - cond.inizal) 
$t=$ time span of change in condition (i.e. trimal - tinivias), and also

$t \geq$ chorus tenure (CT)

Murphy (1994) predicted that males that have lower v, will have longer CTs because they lose condition at a slower rate than males that have higher $v$ (Figure A3.1).

It follows that $v$ may vary due to variation in either $\Delta$ and/or $t$. However, CT sets a minimum below which $t$ cannot vary (i.e. a male with $C T=X$ nights cannot have $t=X-1$ nights, but he may have $t=X+N$ nights, where $N$ varies from 1 to the number of nights in the chorusing season, Figure A3.2). In addition, CT and t are highly positively correlated $(r=0.890, p<0.001$ in my study). This is important because we want to use $v$ to try and explain variation in CT. However, there is a negative relationship expected between $v$ and CT because,

$\mathrm{CT} \propto \mathrm{t}$ (equation A3.2)

and

$v \propto 1 / t$ (equation A3.3)

therefore, $v \propto 1 / C T$ (equation A3.4)

The possibility that $v$ may be unavoidably biased is troubling and calls into question any results based on this variable.

To avoid this problem of bias in $v, I$ regressed $\Delta$ on $t$ and used the residuals of this regression as a new variable, residual condition change. Residual condition change ( $\boldsymbol{\rho})$ is a measure of how much a male's condition has changed relative to the condition change predicted for a given $t$ 
This variable is analogous to $v$ in that it is a measure of energetic efficiency; however, the effect of $\mathbf{t}$ has been partialled out.

There is no theoretical basis for expecting a directional relationship between $\rho$ and CT (unlike between $v$ and $C T$ ) because of the mechanics of least squares regression, which ensure that an equal number of $\Delta$ points lie above and below the regression line of $\Delta$ on $t$ across the range of $t$ values (Figure A3.3). However, if the energetic constraint hypothesis is true, then, when the effects of initial condition, final condition and feeding status on CT have been taken into account in a multiple regression, there should be a positive relationship between $\rho$ and CT (Figure 2 above).

\section{LITERA TURE CITED}

Murphy, C.G. 1994. Determinants of chorus tenure in barking treefrogs (Hyla gratiosa). Behavioral Ecology and Sociobiology 34: 285-294. 


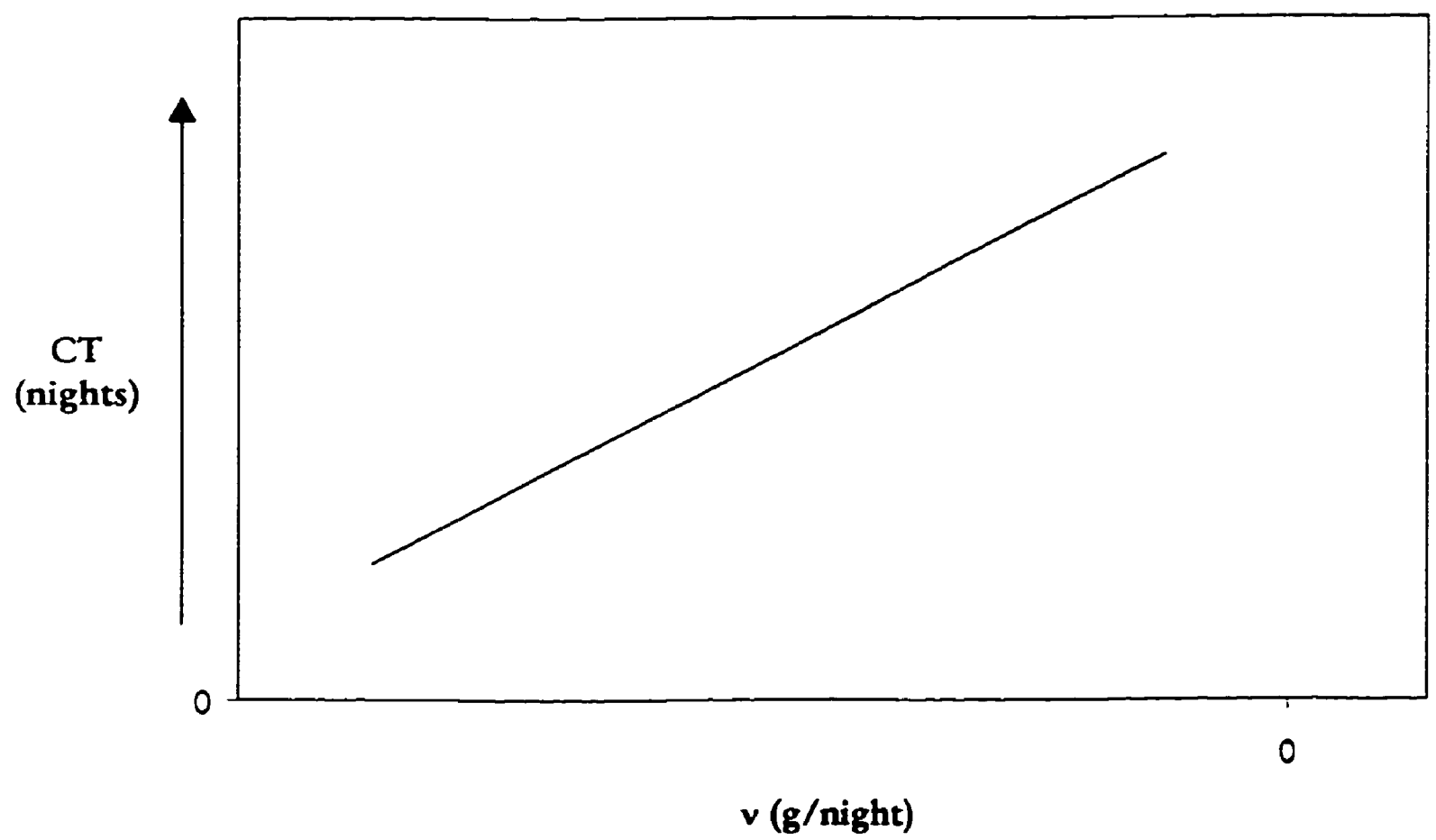

Figure A3.1. Predicted relationship between rate of change in condition ( $v$ ) and chorus tenure (CT). 


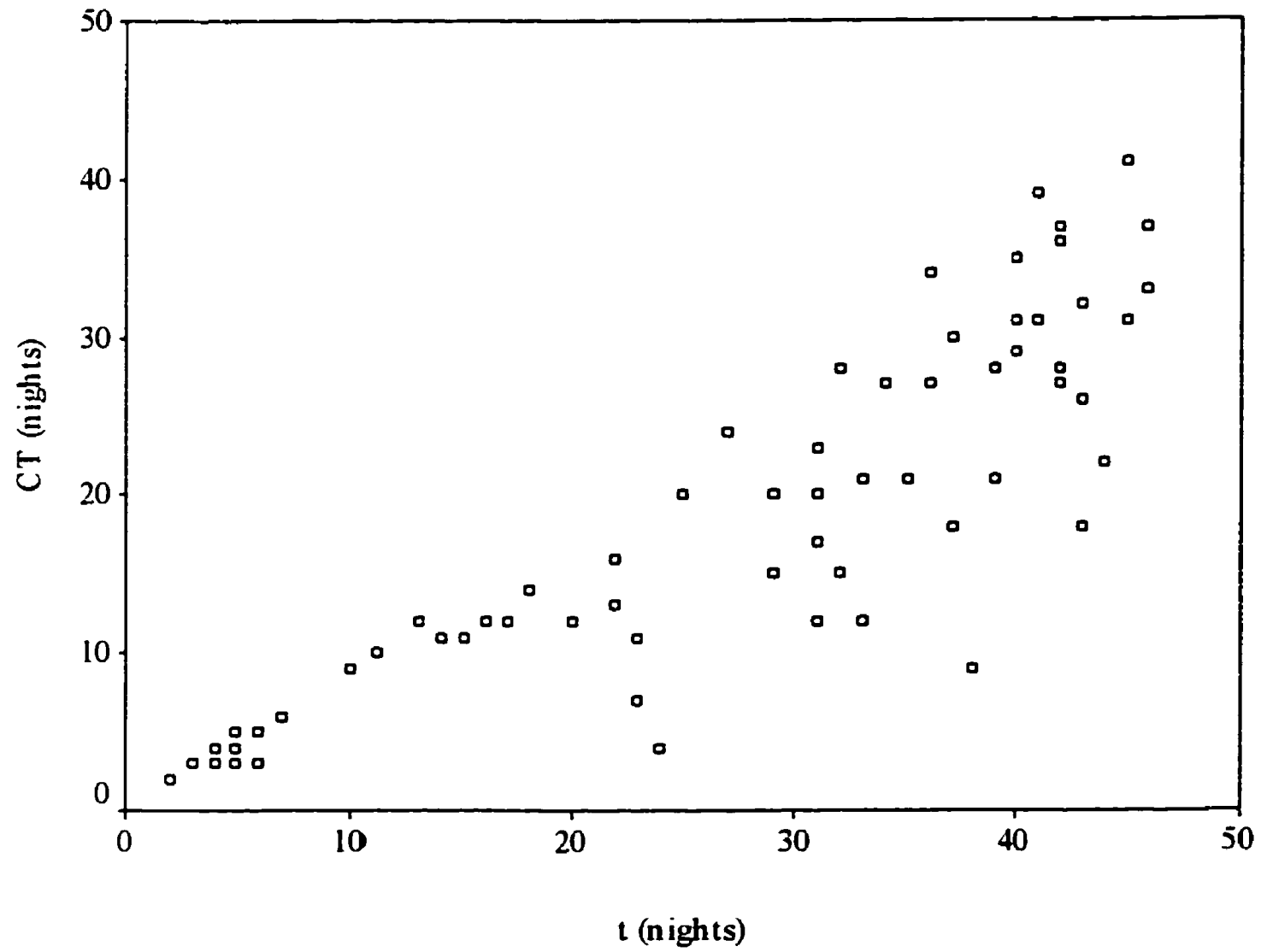

Figure A3.2. Relationship between tenure span (t) and chorus tenure (CT) for the 1998 bullfrog chorusing season on Lake Sasajewun. 


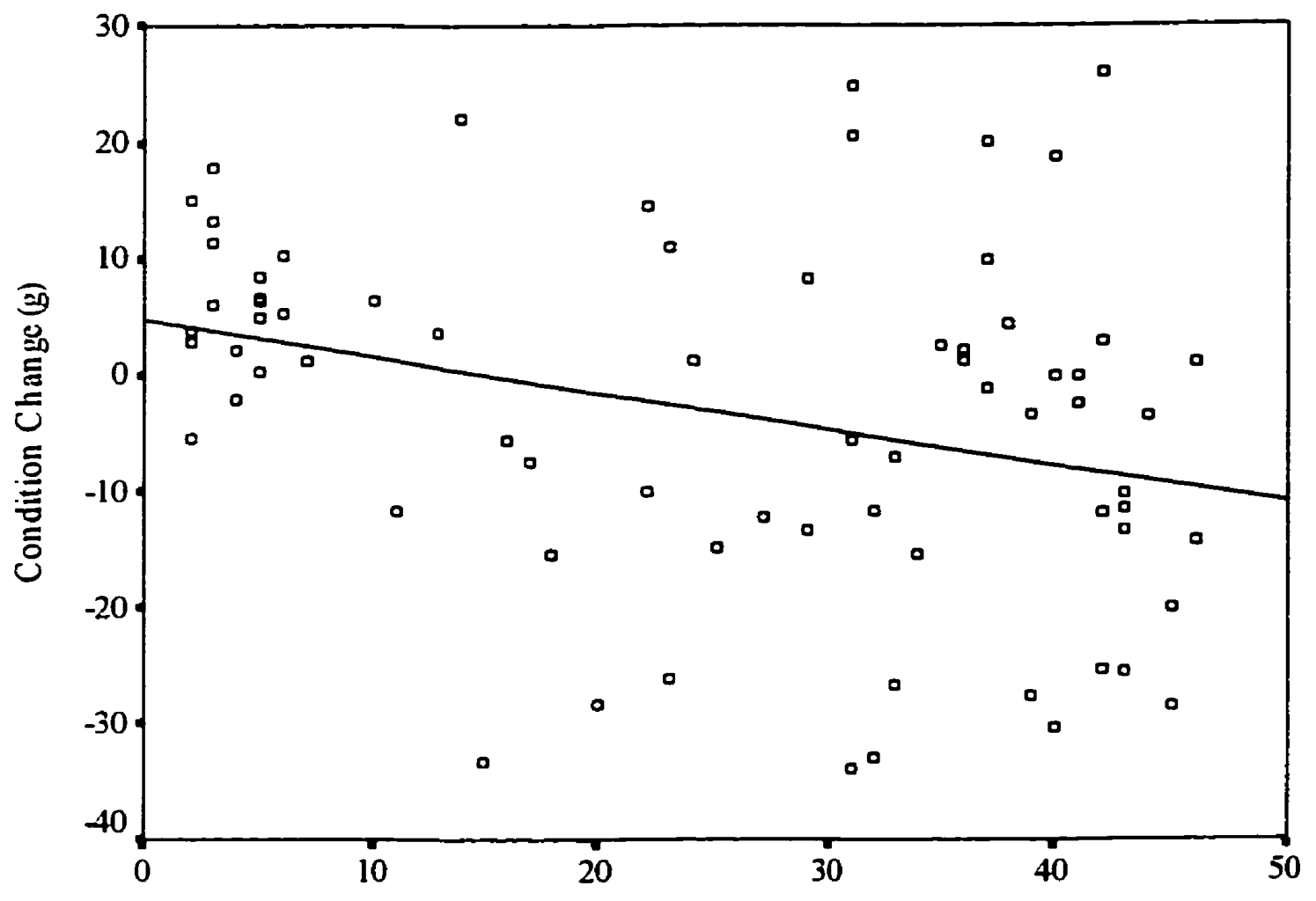

Tenure Span (nights)

Figure A3.3. Plot of condition change $(\Delta)$ versus tenure span $(t)$ with the least squares regression line $\left(F_{1,70}=7.950, p<0.007, \Delta=4.74-0.32 t\right)$ for the 1998 bullfrog chorusing season on Lake Sasajewun. The deviation of each point from the regression line in the $\Delta$ dimension is residual condition change $(\boldsymbol{\rho})$. 